Rev. Hist., N²7, vol. 2, Julio-Diciembre 2020: 265-301

ISSN 0717-8832

https://doi.org/10.29393/RH27-18SANM10018

\title{
"Siempre en las alturas puesto el pensamiento". La Universidad de Concepción en la historia de su himno institucional. ${ }^{*}$
}

\author{
"Always in the heights put the thought". The University of Concepción in the history of its \\ institutional anthem.
}

Nicolás Masquiarán Díaz: ORCID: https://orcid.org/0000-0001-6458-9211**

\section{RESUMEN}

Se expone el proceso de creación y oficialización de los himnos institucionales de la Universidad de Concepción. Como símbolo, es mediador y mediación en diferentes niveles de relación social e institucional, apareciendo como un recurso en la construcción y afianzamiento de los lazos con la comunidad, pero también de círculos sociales en el mundo de la música académica. Con el objetivo central de reconstruir esta historia en el marco del centenario de la institución, se revisaron fuentes documentales de la universidad, especialmente del Archivo Central y Archivo Luis David Cruz Ocampo, además de otros fondos, archivos y prensa escrita, tanto locales como nacionales.

Keywords: himnos, símbolos institucionales, Universidad de Concepción, sociabilidad, historia local

\section{ABSTRACT}

The process of creation and officialization of the institutional anthems for the University of Concepción is exposed. As a symbol, it is a mediator and mediation at different levels of social and institutional relationships showing itself as a resource for the construction and strengthening of the bindings with the community but also inside the social circles in the world of academic music. With the main objective of reconstructing this history within the framework of the institution's centenary, documentary sources from the university were reviewed, especially from the Central Archive and the Luis David Cruz Ocampo Archive, in addition to other background, archives and written press, both local and national.

Keywords: anthems, institutional symbols, University of Concepción, sociability, local history

Recibido: mayo 2020

Aceptado: octubre 2020

\footnotetext{
* Este trabajo es parte de los resultados del proyecto 219.066.007-CA “Recuperación patrimonial de los himnos institucionales de la Universidad de Concepción", auspiciado por la Vicerrectoría de Investigación y Desarrollo de la Universidad de Concepción y elaborado en el marco del centenario de la institución. Sin embargo, es también la culminación de un largo proceso que se inauguró hace una década con el hallazgo de unos manuscritos desconocidos en la Corporación Sinfónica. Mis especiales agradecimientos a Javiera Rodríguez, primera responsable de esta travesía, a Alejandro Gallegos y Fernando Lillo (Departamento de Música, UdeC), al equipo de la Biblioteca Central Luis David Cruz Ocampo (UdeC), en especial a Karen Jara, Carla Silva y Silvia Riquelme, a Haydee Pastén (Oficina de Partes, UdeC), Claudia Arrizaga (AFUDEC), Priscila Osses y Cristina Salazar (Corporación Sinfónica de Concepción) Cecilia Astudillo y Leticia Huerta (Archivo de Música, Biblioteca Nacional), Roberto Doniez Soro (Archivo Enrique Soro), Tomás del Sol y Demetrio Tapia (Pedagogía en Música, UdeC).

** Departamento de Música, Universidad de Concepción. Email: nimasquiaran@udec.cl
} 


\section{Introducción}

Los símbolos institucionales son recursos claves para construir un sentimiento colectivo de pertenencia entre los miembros de una comunidad; contenedores imaginarios de los valores trascendentales y cualidades que la caracterizan. Su carga de sentido se nutre de historias, tradiciones y expectativas que los instituyen como mediadores en la relación de los sujetos con y desde la institución. Además, su materialidad -el objeto, la imagen, el lema, la melodía- abre un espacio de interacción que proyecta esos sentidos más allá de los límites inmediatos de la entidad: las personas que la sostienen, los recintos que la contienen y el territorio en el que influyen. Tanto mayor es su efecto cuando la propia institución, por sus circunstancias históricas, llega a edificarse como símbolo.

Es el caso de la Universidad de Concepción. Como primera universidad chilena en provincia, fue clave en el desarrollo socioeconómico del sur de Chile. Su existencia se justificó a raíz de las demandas productivas específicas de su entorno territorial y la sobrepoblación de estudiantes que aquejaba a las dos únicas universidades que existían en el país a principios del siglo XX, la Universidad de Chile y la Pontificia Universidad Católica de Chile, ambas con sede en la capital. En consecuencia, fue pensada desde Concepción, pero "no solo para beneficio de sus habitantes, sino para los de todo el sur del país"1.

El efecto de su proceso fundacional (1917-19) se encuentra documentado en trabajos que acreditan cómo diversas comunidades, desde el Maule hasta Chiloé, se involucraron con el proyecto ${ }^{2}$. Ofrecieron su respaldo moral y económico pues vieron en él un contrapeso frente a las adversidades que imponía un modelo de Estado unitario y centralista. De ahí en adelante, sus cien años de historia la fueron afianzando como una presencia transversal a las más diversas facetas de la vida ciudadana, desde la materialidad urbana hasta la sociabilidad.

Ese marco privilegiado dio al Himno de la Universidad de Concepción un impulso decisivo para posicionarse como un dispositivo de representación simbólica. En efecto, a los habitantes del Gran Concepción parece resultarles más familiar el himno universitario que el de sus propias ciudades o comunas. Sin embargo, esa misma popularidad resulta engañosa. Da la sensación de que la misma melodía característica, que delimita la jornada desde el Campanil ${ }^{3}$, ha estado presente a lo largo de los cien años de historia institucional. Nada más alejado de la realidad.

\footnotetext{
${ }^{1}$ Cartes, Armando. 2017. Actas Fundacionales Universidad de Concepción, Estudios y notas Vol. I, Concepción, Universidad de Concepción, p. 69

2 Ver DaCosta, Miguel. 1995. Crónica fundacional de la Universidad de Concepción, Concepción, Universidad de Concepción.

${ }^{3}$ El Campanil, la "torre del reloj" diseñada por Enrique San Martin y erigida en 1943 en el corazón del campus, es el símbolo arquitectónico más característico de la Universidad de Concepción. Diariamente toca el estribillo del actual Himno de la Universidad de Concepción a las 8:00, 12:00, 14:00 y 18:00 horas, marcando el inicio y fin simbólicos de
} 
El presente trabajo propone una historia del himno de la Universidad de Concepción. Se trata de un relato con bastantes más altibajos de los que deja sospechar su indudable presencia actual como sello de identidad local. Para construirlo, interpreto el himno, en diferentes etapas de su devenir, como un objeto susceptible de visibilizar las intrigas que se entretejen entorno a él ${ }^{4}$. Dentro de esa urdimbre, desenmaraño algunos de los hilos que se entrecruzan para deducir y exponer las lógicas subyacentes recurriendo a una sucesión de lecturas de orientación microhistórica, corriente cuya caja de herramientas ya ha demostrado su aplicabilidad en el terreno la musicología histórica ${ }^{5}$.

La universidad y sus autoridades, la comunidad local y los músicos nacionales, entre otros, aparecerán acá como agentes que se involucran en el proceso desde diversos universos sociales y con diversos intereses, en mayor o menor medida explícitos. Algunos de esos universos se constituyen -o instituyen- como círculos sociales. En consecuencia, cuenta acá invocar la sociabilidad como un aspecto relevante del análisis, entendida como una aptitud que los diversos actores presentan para construir vínculos con un objetivo común ${ }^{6}$. Por supuesto, con las consideraciones pertinentes al contexto que nos atañe: principalmente local y en diferentes momentos del siglo XX. Además, entendiendo que ese objetivo común también es mediado por motivaciones individuales.

El trabajo se concentra en tres aspectos clave. El primero es ofrecer una reconstrucción documentada y coherente de los acontecimientos que llevaron a creación y oficialización de la pieza musical. Un asunto transversal, pero más evidente y directo en las dos primeras secciones. En las siguientes, propongo el proceso de legitimación del himno universitario como posibilidad de negociación entre la institucionalidad musical hegemónica, en Santiago, y la institucionalidad local emergente. Analizo especialmente aspectos de sociabilidad que se despliegan más allá del radio local y que son influyentes sobre las determinaciones que se toman en una institución de provincia.

Por último, argumento cómo la vigencia y trascendencia simbólica del himno actual, uno de entre varias versiones oficiales, ha sido mediada por las condiciones concretas de reproducción y circulación que fue capaz de proporcionar ese contexto local. En contraste con lo anterior, en esta última etapa será el himno en sí, socialmente legitimado, el que se presente como un insumo de negociación frente a la autoridad.

cada jornada académica. Esta presencia constante en la cotidianeidad universitaria sin duda ha aportado a construir un sentido de identidad asociado a la melodía.

${ }^{4}$ Cf. Veyne, Paul. 1984. Cómo se escribe la historia. Foucault revoluciona la historia, Madrid, Alianza.

5 Musri, Fátima. 2013. "Definiciones y ayudas metodológicas para una historia local de la música", en Revista del Instituto Superior de Música, №14, Santa Fe, pp. 51-72.

${ }^{6}$ Agulhon, Maurice. 2009. El círculo burgués seguido de Una pequeña biografía intelectual. Buenos Aires, Siglo XXI. 


\section{Apuntes sobre el escenario fundacional}

La Universidad de Concepción se levantó como un proyecto a contracorriente. Su existencia representaba una victoria de la élite local contra poderes e intereses "nacionales". Favorecía la autonomía provincial y, por ende, representaba una amenaza para los grupos de poder asentados en la capital. No es de extrañar que, aun cuando la iniciativa fuese recibida con entusiasmo por el presidente Sanfuentes, encontrara una férrea oposición en el parlamento ${ }^{7}$, fuertemente vinculado con las familias influyentes de Santiago.

La empresa iniciada por el Comité Pro Universidad y Hospital Clínico Regional no concluyó con la fundación. Las aulas universitarias se abrieron antes de contar con una aprobación oficial del gobierno ${ }^{8}$. Los primeros años de la institución se concentraron en resolver asuntos prácticos: en atender los requerimientos más inmediatos que imponían las carreras en marcha y satisfacer la demanda de profesionales en sur del país, al tiempo que internamente se conciliaban las expectativas de los diferentes grupos que se disputaban el predominio sobre este nuevo espacio de poder, especialmente la Iglesia católica y la masonería.

Todo esto se fue superando desde una conciencia sobre la responsabilidad de representar una visión de avanzada respecto del país, la ciudadanía, la educación y la cultura, en un instante de la historia donde -transcurridos pocos años del Centenario de la República-todavía pesaban las preguntas sobre el Chile que se aspiraba construir.

En ese marco, los símbolos representativos fueron un asunto de especial interés y compromiso para la comunidad universitaria, aunque la inquietud por definirlos aparece recién documentada por primera vez a cuatro años de la fundación. Ciertamente, una etapa de relativa estabilidad en contraste con los años anteriores.

A partir de su $112^{\circ}$ sesión, el 6 de junio de 1923, el Directorio decidió "comisionar a los señores Virginio Gómez, Salvador Gálvez, Abraham Melo, Samuel Zenteno, Nelson Bahamonde

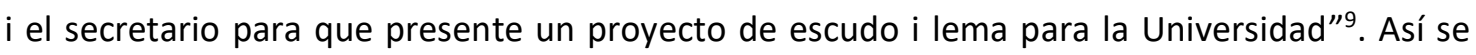
inauguró un largo proceso de cuatro décadas, donde el único superviviente fue el escudo, pues el lema y el himno tuvieron una deriva íntima que, como veremos a continuación, no se resolvería solo con decretos y concursos.

\footnotetext{
7 Molina, Enrique. 1956. Discursos Universitarios, Santiago, Nascimiento, p. 10. Algunas alusiones también figuran en DaCosta, M. 1995. Crónica fundacional...

${ }^{8}$ Si bien los primeros cursos se inauguraron a mediados de marzo de 1919 (Da Costa, M. 1995. Crónica fundacional..., pp. 211-212), su normativa fue aprobada recién el 14 de mayo, considerada fecha fundacional.

${ }^{9}$ Archivo Central (AC), Universidad de Concepción (UdeC), Actas de Directorio (AD). Libro 2, folio 39. $112^{\circ}$ Sesión 6 de Junio de 1923.
} 


\section{La génesis del himno institucional}

La intención de obtener un himno para la Universidad de Concepción conoció sucesivos fracasos. En 1923 el Directorio Corporativo decidió,

" $7^{\circ}$ A Abrir un concurso para la elección de un himno de la Universidad. Se establece un premio de quinientos pesos para la composición que resulte elejida. El plazo para la presentación de los trabajos será hasta el 31 de marzo de 1924. El jurado encargado de pronunciarse sobre los trabajos quedará compuesto de las siguientes personas: señores Enrique Molina, Samuel Zenteno, Abraham Melo, Enrique Marshall i don Luis D. Cruz Ocampo". ${ }^{10}$

Nada más sabemos sobre este certamen. Hasta la fecha no se conocen indicios de que haya llegado a realizarse siquiera. En todo caso, siete años más tarde encontramos una nueva tentativa. Se determinó entonces "abrir un concurso para un Himno de la Universidad de Concepción; y resolver en una sesión próxima acerca del monto del premio y de las personas que han de formar el jurado"11. Días más tarde se definió,

"1 ${ }^{\circ}$ _ Fijar la cantidad de dos mil pesos para premiar la letra del Himno de la Universidad y nombrar para jurado del concurso respectivo a los señores: Enrique Molina, Julio Parada, Eliseo Salas, Abraham Melo, Guillermo Bembow y un estudiante que será designado por la Federación" ${ }^{12}$

Nada sugiere que esa segunda intención haya llegado a buen puerto. En diciembre de 1936 el asunto volvió a ser tratado por el Consejo Superior, esta vez por iniciativa de la Federación de Estudiantes (FEC), quienes solicitaron "reapertura del concurso para proveer a la Universidad de Concepción de un himno universitario y de una marcha estudiantil"13.

En la respuesta del Consejo se aclara que el certamen de 1930 había sido declarado desierto $^{14}$ y que en ese momento la composición del poema que pasaría a ser el himno institucional se encontraba encargada a uno de los consejeros ${ }^{15}$.

\footnotetext{
${ }^{10}$ AC, UdeC, AD. Libro 2, folio 68. 124 Sesión 17 de Octubre de 1923.

${ }^{11}$ AC, UdeC, AD. Libro 4, folio 246. Sesión en 30 de Abril de 1930.

12 AC, UdeC, AD. Libro 4, folio 254. Sesión en 7 de Mayo de 1930.

${ }^{13}$ AC, UdeC, Actas del Consejo Superior (ACS). Libro 4, folio 144. Sesión en $1^{\circ}$ de Diciembre de 1936.

${ }^{14}$ Esta determinación se confirma además en AC, UdeC, ACS. Libro 4, folio 204. Sesión en 25 de agosto de 1937. Una mención de la prensa añade además que la decisión se tomó "por carecer de méritos suficientes los diversos trabajos presentados en esa ocasión" ("El concurso abierto para la letra del himno de la Universidad quedará c errado (sic) el $1^{\circ}$ de septiembre". Biblioteca Central Luis David Cruz Ocampo (BC), UdeC, La Patria, 23 de agosto de 1938, p. 6).

15 " $10^{\circ}$ _ Encargar al secretario la redacción del Himno de la Universidad". AC, UdeC, AD. Libro 5, folio 206. Sesión 14 de Enero de 1931. En efecto, Félix Armando Núñez firma como Secretario en esa sesión del Directorio.
} 
Se trataba de Félix Armando Núñez Beauperthy (1897-1972). Nacido en Venezuela, en 1914 se trasladó a Chile becado por el gobierno para formarse en la Escuela Normal José Abelardo Núñez (1914-15). Desde ahí pasó al Instituto Pedagógico de la Universidad de Chile (1916-19) donde se graduó de Profesor de Castellano con máxima distinción. Apenas recibido, inició una promisoria carrera como poeta, crítico y ensayista, inaugurada con la publicación de los poemarios La voz íntima y La luna de otoño. En ese periodo entabló una amistad con la poetisa Gabriela Mistral, con quien sostuvo correspondencia entre 1919 y 1921, evidenciando en ella su vínculo con el medio literario nacional ${ }^{16}$. Agreguemos a lo anterior que su prosa poética "Canciones de la soledad invencible" apareció publicada en el primer ejemplar de Revista Atenea $(1924)^{17}$, de la que más tarde integró el cuerpo directivo. Su oficio le valió a la larga el Premio Nacional de Literatura en Venezuela (1953) por El poema de la tarde, y la Orden al Mérito Bernardo O’Higgins, otorgada por el Ministerio de Relaciones Exteriores a aquellos extranjeros que han prestado servicios destacados al país.

Su remarcable expediente profesional temprano y el éxito de sus primeras publicaciones deben haber persuadido a las autoridades universitarias de integrarlo a la planta docente. En 1921 ingresó a la institución como profesor de literatura, filosofía y estética literaria, además de pro-secretario. A partir del año siguiente aparece desempeñándose como Secretario General, cargo en el que se mantuvo hasta por lo menos 1931, cuando alcanzó el cargo de Decano de Filosofía y Educación. Esto explica que aparezca primero integrando el Directorio y, algunos años más tarde, el Consejo Superior.

Aunque llama la atención que no se haya reivindicado mayormente la presencia de Félix Armando Núñez en la ciudad ${ }^{18}$, es fácil entender por qué la universidad confió en él para la composición del texto del himno. El vate, desde una mirada romantizada, es quien posee la capacidad de representar la realidad trascendental. Sin embargo, cuando en una sesión de 1936 fue consultado al respecto, descubrimos que el encargo nunca se tradujo en una propuesta concreta que llegara a manos de las autoridades por causas muy humanas. El académico se excusó en los términos que siguen:

“El Consejero señor Núñez explica que su situación ha sido algo delicada en este punto por cuanto el acuerdo en referencia establecía que se le pagarían los dos mil pesos que se habían acordado por la letra, lo que importaba que su trabajo fuese superior a los que se habían

\footnotetext{
16 Hodge, Eduardo. 2014. "Félix Armando Núñez en la pluma de Gabriela Mistral: Chile y Venezuela unidos en el tiempo", Tiempo y Espacio, 62, 77-92.

${ }^{17}$ Atenea №1, 45-47. Se trata de una publicación impulsada por Enrique Molina para exponer el trabajo intelectual de los académicos de la Universidad de Concepción. Ha circulado ininterrumpidamente hasta la actualidad.

18 Una de las principales historias locales apenas lo reseña con las siguientes palabras: "Félix Armando Núñez, venezolano, entrega por aquellos años lo más selecto de su poesía, de canto puro y grave, que le sobrevivirá". Campos H., Fernando. 1979. Historia de Concepción 1550-1970, Santiago, Editorial Universitaria, p. 301.
} 
presentado. Además, dice el señor Núñez, un himno resulta, fuera de las condiciones que tan benévolamente el Consejo ha admitido en él, de un momento de disposición especial del ánimo del autor. Las numerosas preocupaciones de trabajo que ha tenido, añade, lo han hecho ir postergando este compromiso con la Universidad que para él constituye una distinción honrosísima"19.

Considerando las fechas es posible que, buenas intenciones aparte, las responsabilidades docentes y administrativas, además de las nuevas condiciones que impuso su decanatura desde 1931, sí hayan tenido un efecto negativo sobre la disponibilidad de tiempo y "disposición especial de ánimo" a la que alude Núñez. En efecto, se constata una merma general en su producción literaria entre la década de 1920 y su retorno a Venezuela, hacia 1940 o 41.

No obstante, el Consejo mantuvo su confianza en el poeta, quien en principio consintió persistir en la empresa, ahora sin comprometer remuneración y "siempre que una comisión dé el visto bueno a su trabajo. Dicha comisión quedó formada, a propuesta del señor Núñez, por el Presidente señor Molina y los señores Alcibíades Santa Cruz y Julio Parada Benavente" ${ }^{20}$. Sin embargo, al poco tiempo desistió de forma definitiva, motivando en el rector Enrique Molina una nueva tentativa para conseguir el tan postergado símbolo universitario:

“El señor Núñez ha pedido al señor presidente que lo releve de este compromiso y estima oportuno abrir un nuevo concurso. Después de un ligero cambio de ideas sobre la materia presentada por el señor Molina se acordó proceder en la forma indicada y nombrar un jurado compuesto por don Abraham Melo, Alcibíades Santa Cruz, Julio Parada, señora Corina Vagas de Medina y del presidente de la Federación de Estudiantes, quienes establecerán las bases de este concurso y las presentarán al Consejo en una sesión próxima ${ }^{21 "}$.

Y es así como, tras un preámbulo de más de una década, el 25 de agosto de 1937 recién entramos en terreno de conseguir un primer himno oficial.

El certamen acordado por el Consejo Superior se hizo público el 5 de mayo de 1938 (Imagen 1), con un primer anuncio publicado en diario El Sur, que hasta el 18 de agosto de ese año fue replicado una veintena de veces en diversos medios de prensa local y nacional, incluidos $L a$ Patria, El Mercurio, La Nación, Diario Ilustrado, La Hora y El Imparcial, hasta donde tenemos noticia. Es decir que, en esta ocasión, si se procuró un fuerte respaldo publicitario para el concurso.

\footnotetext{
${ }^{19}$ AC, UdeC, ACS. Libro 4, folio 144. Sesión en $1^{\circ}$ de Diciembre de 1936.

20 /bíd.

${ }^{21}$ AC, UdeC, ACS. Libro 4, folio 204. Sesión en 25 de Agosto de 1937.
} 


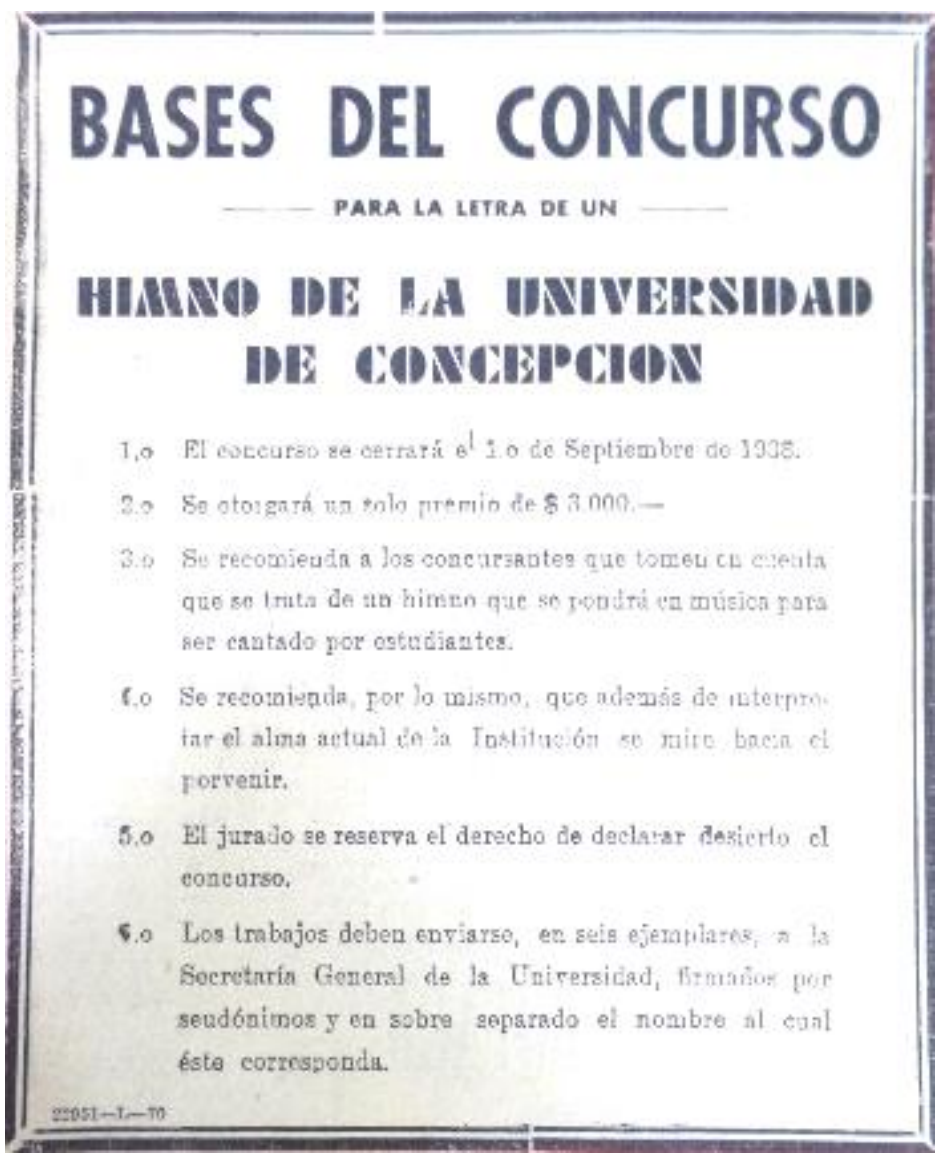

Imagen 1. Bases del concurso por el Himno de la Universidad de Concepción. Primera publicación. BC, UdeC. El Sur, 5 de mayo de 1938, p. 5

El $1^{\circ}$ de septiembre de ese año se dio por cerrada la recepción de trabajos, que según la prensa local sumaron más de cuarenta ${ }^{22}$, y pasaron a manos de un jurado compuesto por el "Rector de la Universidad señor Enrique Molina, Director de la Escuela de Ciencias Jurídicas y Sociales señor Julio Parada B., Dr. Alcibíades Santa Cruz, señora Corina Vargas de Medina, señor Abraham Melo y P. y Presidente de la Federación de Estudiantes, señor Américo Albala" ${ }^{23}$. Este

22 BC, UDEC: La Patria, 31 de agosto de 1938, p. 6; La Patria, 29 de octubre de 1938, p. 6.

Cerca de la mitad de las propuestas recibidas a este concurso se conservan actualmente en el Archivo Luis David Cruz Ocampo (ALDCO), AVSCH-SU-H, Sala Chile, BC, UdeC. Un análisis más detallado de sus contenidos entregaría más detalles sobre la percepción de la comunidad hacia la institución.

${ }^{23}$ BC, UdeC, El Sur, 29 de octubre de 1938, p. 6. 
último fue posteriormente excluido de la comisión debido a una irregularidad en la posesión de su cargo ${ }^{24}$.

Tanto las condiciones del concurso, de alcance nacional y con un alto costo asociado ${ }^{25}$, como la designación del jurado, por su diversidad de representantes, dan cuenta de la voluntad institucional de abrirse hacia una comunidad cada vez más amplia. Una intención que parece haberse recibido positivamente, pues las postulaciones provinieron de diferentes puntos del país $y$, al mismo tiempo, fueron capaces de levantar un sentido de localismo manifiesto en algunos de los textos propuestos (como los ejemplos que se transcriben a continuación), donde Concepción se presenta ante el resto del país o el mundo a través de su Universidad, o algunos de los seudónimos escogidos por sus autores. Entre estos últimos encontramos algunos tan variopintos como Rosicler, Rouget de l'Isle, Epiménides, Archiduque, Cenit, Sir Galahad, BenarJu-Addan, algunos más mundanos como Laurel y Hardy o Picha Caluga ${ }^{26}$, y aquellos más locales como Sureño, Andalién y Pencófilo.

Zurca (sic) el cielo en carruaje de esmeraldas

el noble lema de la Universidad, que Concepción en medio de guirnaldas

muestra con orgullo a la humanidad. ${ }^{27}$

Adelante, plantel de cultura.

Concepción, que es la reina del sur,

te confía la suerte futura

del que busca en tus aulas más luz.

\footnotetext{
24 "...ha quedado excluido en virtud de un acuerdo del Consejo respecto de la Federación, con la cual ha cortado relaciones por estar presidida por un ex alumno". BC, UdeC, La Patria, 29 de octubre de 1938, p. 6.

${ }^{25}$ En un correo interno de la Secretaría General figuran algunos costos por la publicación de avisos en prensa, que van desde \$ 155 en La Patria (Concepción), hasta \$ 433 en El Mercurio (AC, UdeC, Secretaría General, Correspondencia Recibida 2018-II, 31 de agosto). Se habrían publicado 24 anuncios entre mayo y agosto de 1938, de los cuales pude confirmar 21 en Hemeroteca, BC, UdeC, y la Sección de Periódicos y Microformatos de la Biblioteca Nacional (BN). Aunque es preferible no aventurar una cifra, es evidente que el costo por concepto de publicidad superó con mucho la suma destinada al premio.

26 "Laurel y Hardy" en referencia a Stan Laurel y Oliver Hardy, dúo cómico estadounidense popularizado a través de la industria cinematográfica, coloquialmente conocidos como "el gordo y el flaco". "Picha caluga" o "picho caluga" es un modismo chileno utilizado para expresar un juicio positivo. Podría traducirse como "ideal", "excelente" o "muy bueno".

${ }^{27}$ BC, UdeC, ALDCO AVSCH-SU-H-07. LUDACHA. Himno a la "Universidad de Concepción" (Estrofa 1).
} 


\section{De la fértil comarca sureña}

paraíso es la universidad,

cuyos frutos obsequia el que enseña

en sus clases con tino y bondad. ${ }^{28}$

Al margen del majestuoso Bio-Bío

En los confines de la indómita Araucanía

En humilde cuna naciste

Alma Mater penquista. ${ }^{29}$

La presencia de tres piezas con partitura incluida (Imagen 2), remitidas por Pencófilo, BenarJu-Addan y Laurel y Hardy, pese a que el llamado fue exclusivamente a proponer el texto, es sugestiva respecto del entusiasmo que esta competencia llegó a despertar y el interés de los aspirantes por trascender como nombres detrás de los símbolos institucionales. Los dos primeros incluyen además un comentario justificando su gesto.

"En el deseo de ampliar este trabajo he compuesto un trozo musical de fácil y sencilla melodía con el cual se cantaría el HIMNO que expongo al elevado criterio del Honorable Jurado. Es una partitura para piano y, por lo tanto, susceptible de orquestarse o instrumentarse para banda; trabajo que puedo hacerlo Personalmente, llegado el caso de tener éxito en este Concurso". ${ }^{30}$

"Y como soy no solo literato sino también facedor de notas, he cedido a la tentación de dar yo mismo relieve lírico a mis versos en un rápido apunte, que ojalá pudiera desarrollar si vuestro beneplácito así lo estimase". ${ }^{31}$

Hasta ahora, no hay indicios de quienes podrían ser los nombres reales tras estos seudónimos.

\footnotetext{
${ }^{28}$ BC, UdeC, ALDCO AVSCH-SU-H-10. PEDRO VALDIVIA. Concurso Himno Universitario de Concepción (Coro y estrofa 1). Las cursivas son añadidas.

${ }^{29} \mathrm{BC}, \mathrm{UdeC}, \mathrm{ALDCO}$ AVSCH-SU-H-11. Picha Caluga. Himno Universitario Alma Mater Penquista (Estrofa 1, fragmento).

${ }^{30} \mathrm{BC}, \mathrm{UdeC}$, Archivo ALDCO AVSCH-SU-H-14. Nota al jurado de Benar-Ju-Addan.

${ }^{31}$ BC, UdeC, Archivo ALDCO AVSCH-SU-H-05. Nota al jurado de Pencófilo.
} 

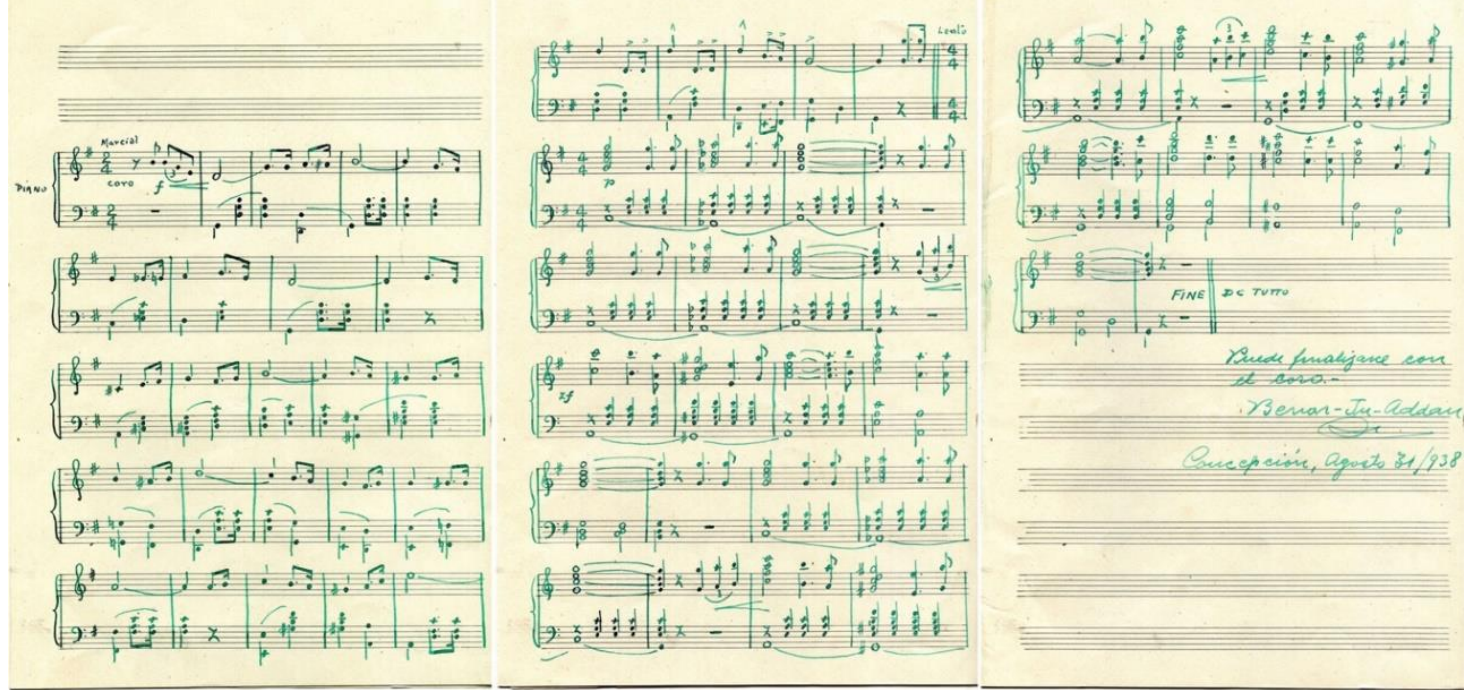

Imagen 2. Partitura enviada por Benar-Ju-Addan. BC, UdeC, Archivo AVSCH-SU-H-14.

Tal podía ser la expectación que generó este concurso entre la comunidad que el 10 de diciembre de ese año se recibió una misiva en la Secretaría de la Universidad de la que extraigo el fragmento a continuación:

"Agradeceré a Ud. contestarme respecto a una duda que me asiste [respecto] tocante al Concurso Pro Himno a la Universidad. Una persona me aseguró que había visto publicado el fallo de dicho Concurso y yo [aseguro] sostengo que no, pues recuerdo haber leído una publicación anunciando el próximo fallo por el jurado respectivo". ${ }^{32}$

La anhelada respuesta debió esperarse hasta el mismísmo día de Navidad ${ }^{33}$. En primer término, se coronó ganador el literato, periodista y diplomático tongoyino Víctor Domingo Silva (1882-1960). El poeta había figurado entre los favoritos del país durante las décadas de 1910 y $1920^{34}$ y a la sazón ejercía como asesor literario para la célebre revista Zig Zag y redactor del diario La Opinión de Santiago ${ }^{35}$. Participó bajo la denominación de Ñanku ${ }^{36}$, seudónimo con el que aludía al protagonista de su reciente obra El Mestizo Alejo (1934) con el que además hacía

\footnotetext{
32 AC, UdeC, Correspondencia Recibida, 1938-II, 000362. Las palabras en corchetes aparecen tachadas en el manuscrito.

33 "Los estudiantes universitarios tendrán ahora su himno propio". La Patria, 25 de diciembre de 1938, p. 6

${ }^{34}$ Subercaseaux, Bernardo. 1997. Historia de las ideas y la cultura en Chile (II), Santiago, Editorial Universitaria, pp. 97-98.

35 Venegas, Fernando. 2002. Víctor Domingo Silva Endeiza: Una vida sin detenciones (1882-1960), Limache, Autoedición auspiciada por el Consejo Nacional del Libro y la Lectura.

36 En algunas fuentes aparece como Ñandú o Ñankú. Esta última, junto con Ñamco, aparecen como variantes del mapudungu para la palabra ñamku, aguilucho, nombre que habría recibido Alejandro de Vivar, el mestizo Alejo, entre los mapuches.
} 
un guiño a la zona del Biobío. Aunque tal elección bien podría haber sido sugestiva respecto de la identidad real del concursante. Y no está de más agregar que el mes previo a la definición del premio había asistido a la Universidad de Concepción para dictar conferencias ${ }^{37}$.

No obstante este pronunciamiento del jurado y contra todo pronóstico, también contó con una alta recomendación el poema compuesto por Arnaldo Gamonal Lagos ${ }^{38}$, con el seudónimo Labrador. Frente a esta sugerencia, el Directorio de la Universidad optó por declarar ex aequo $^{39}$. Paradójicamente, ambos ganadores postularon desde la capital.

De los textos premiados, el de Víctor Domingo Silva es el que se conserva hasta la actualidad, aunque fue modificado en el tiempo hasta verse reducido a solo su estribillo y primera estrofa. El de Arnaldo Gamonal permaneció en el olvido hasta ahora. Ambos poemas se incluyen en su versión íntegra en el apéndice de este trabajo.

\section{La musicalización de los himnos}

Al año siguiente del-por fin-exitoso concurso, el 24 de mayo de 1939, Enrique Molina recuerda al Consejo Superior de la Universidad de Concepción el asunto de los himnos:

"Propone que se abra un concurso privado. Las letras de las estrofas premiadas se enviarán a los que tomen parte de dicho concurso. Se esperará hasta fines de septiembre para decidir sobre el resultado y se propondrá al Directorio que dé la suma de tres mil pesos para cada uno de los trabajos premiados si así lo estiman conveniente los señores miembros del Consejo" ${ }^{40}$.

Se acordó realizar una segunda convocatoria, esta vez de índole privada "entre los mejores compositores del país, para dotar de música a los dos himnos premiados en el certamen del año último" ${ }^{41}$, además de solicitar al Directorio un ítem de $\$ 6.000$ para ofrecer un premio de $\$ 3.000$ por la mejor musicalización de cada uno de los poemas ganadores. El Directorio, que al parecer había retomado el tema previamente, sugirió insinuar a la Sociedad de Compositores de Santiago "que se interesen por el Himno" 42.

La referida mención a la "Sociedad de Compositores de Santiago" sugiere un desconocimiento respecto del proceso de reconfiguración institucional que atravesaba la

\footnotetext{
37 "Víctor Domingo Silva dictará dos conferencias", La Patria, 5 de noviembre de 1938. Noticias alusivas aparecen también los días siguientes.

${ }^{38}$ En algunas fuentes figura como Arnoldo, Armando o Arturo. Nos ceñimos al nombre que se imprimió más tarde en la partitura oficial.

${ }^{39}$ AC, UdeC, AD. Libro 11, folio 86. Sesión en 28 de Diciembre de 1938.

${ }^{40}$ AC, UdeC, ACS. Libro 5, folios 34-35. Sesión en 25 de Mayo de 1939.

${ }^{41}$ AC, UdeC. Expediente 81-370, Compra derechos intelectuales sobre el himno universitario al Sr. Wilfried Junge Eskuche. Carta de Enrique Molina a Próspero Bisquertt, 9 de junio de 1939. (Copia adjunta a carta de Mercedes Bisquertt al Carlos von Plessing, Rector de la Universidad de Concepción, 25 de noviembre de 1986).

${ }^{42}$ AC, UdeC, AD. Libro 11, folio 173. Sesión en 24 de mayo de 1939.
} 
música clásica chilena. Para entonces existían en la capital dos instituciones de esa naturaleza: la Sociedad de Compositores Chilenos (SCCH) y la Asociación Nacional de Compositores (ANC). Un punto sobre el que será necesario volver más adelante. No obstante, a fin de estimular la participación en el concurso, fueron enviadas invitaciones directas rubricadas por el rector, en los términos que siguen:

"Distinguido señor,

el consejo de esta Universidad ha acordado abrir un concurso privado entre los mejores compositores del país para dotar de música a los dos himnos premiados en el certamen del año último.

El concurso se cerrará el 31 de Agosto próximo. El premio acordado es de \$3.000.- para cada una de las composiciones musicales premiadas. Los trabajos deberán ser enviados a la Secretaría General de la Universidad con la música escrita para orquesta o una reducción para piano facilmente instrumentable [sic].

Las composiciones deberán venir firmadas con seudónimo y en sobre cerrado el nombre de la persona a quien corresponda.

Tengo el agrado de incluirle copia de los himnos a que me he referido y le ruego tener a bien interesarse por este concurso y tomar parte en él". ${ }^{43}$

No se han encontrado registros sobre los compositores a quienes fueron dirigidas las invitaciones. Pero hasta donde sabemos, fue remitida hacia la Universidad de Concepción una lista de compositores por parte de la Facultad de Artes de la Universidad de Chile ${ }^{44}$. Finalmente, solo cuatro autores llegaron a interesarse y enviaron sus propuestas: Javier Rengifo, Héctor Melo Gorigoytía, Enrique Soro y Próspero Bisquertt ${ }^{45}$. Dado que entre ellos hay miembros de la ANC y la $\mathrm{SCCH}$, podemos suponer que no se llegó a discriminar entre organizaciones.

El jurado del certamen estuvo integrado por Arturo Medina, director de coros, Alfonso Izzo, profesor de teoría musical, y Roberto Ide, pianista ${ }^{46}$. La comisión se debió valer de este último para acceder a una audición de las piezas, pues habían sido solicitadas "para orquesta o una reducción para piano fácilmente instrumentable" ${ }^{47}$. El jurado dirimió en favor de Próspero Bisquertt, doblemente galardonado por sus musicalizaciones sobre ambos textos, en una decisión que no estuvo exenta de controversias.

\footnotetext{
${ }^{43}$ AC, UdeC. Expediente 81-370. Carta de Enrique Molina a Próspero Bisquertt, 9 de junio de 1939.

${ }^{44}$ AC, UdeC, ACS. Libro 5, folio 111. Sesión en 20 de Diciembre de 1939.

45 BC, UdeC, ALDCO AVSCH-SU-H-25. Fichas manuscritas con datos sobre el concurso para la musicalización del Himno de la Universidad de Concepción.

${ }^{46}$ AC, UdeC, ACS. Libro 5, folio 91. Sesión en 27 de Septiembre de 1939. Algunos apellidos aparecen transcritos con errores en las actas; fueron contrastados con otras fuentes.

${ }^{47}$ AC, UdeC. Exp. 81-370. Carta de Enrique Molina a Próspero Bisquertt, 9 de junio de 1939.
} 
Bisquertt, como veremos más adelante, gozaba de cierto reconocimiento en el ambiente de la música nacional. Además, poseía oficio en la composición de himnos; ya se había adjudicado previamente los de la Escuela Militar (1917), la Universidad Técnica Federico Santa María (1931) y la Escuela de Artes y Oficios (actual Universidad de Santiago de Chile, 1931). No obstante, consta en las actas del Consejo Superior que la primera opción no había sido otorgarle el premio, sino declarar el concurso desierto pues "ninguno de los concursantes ha presentado una composición aceptable" 48 .

Sin embargo uno de los miembros del jurado manifestó privadamente que el mejor de todos los himnos corresponde al seudónimo de Mario Neti que ha resultado ser el compositor señor Próspero Bisquertt. "Por esta razón y teniendo presente que no es posible llamar a nuevo concurso pues ya se han presentado los mejores compositores del país. El Rector estima que se podría pedir al señor Bisquertt que modifique la música de su himno y aceptarlo por ser el mejor. Así quedó acordado" ${ }^{49}$.

Por supuesto, el argumento que clausura la posibilidad de un nuevo himno resulta débil. Difícilmente cuatro compositores iban a completar la nómina de profesionales activos en el país, que deben haber alcanzado a lo menos una treintena considerando los pertenecientes a la ANC y la SCCH. Más bien debió apremiar la necesidad de dar cierre a un proceso que llevaba 16 años sin resolución. Pero incluso en esos términos, el punto verdaderamente cuestionable es que ya se conociera el nombre detrás del seudónimo, pues tratándose de un concurso ciego, con los nombres resguardados por sobres sellados, este no debiera haberse revelado hasta que la decisión final estuviera tomada.

El asunto no se agotó ahí. Para el mes siguiente nos enteramos de que Bisquertt ha enviado las correcciones requeridas por el jurado, pero la nueva versión sigue siendo insatisfactoria y la formalización del premio sigue pendiente. La redacción del acta resulta algo confusa, pero se colige que le han sido solicitadas las modificaciones al autor pese a que aún no se le ha declarado oficialmente ganador, avalándose en el acuerdo de aceptación alcanzado en la sesión del 22 de noviembre. Sin embargo, el ambiguo informe oficial emitido por el jurado viene a enturbiar más la situación, hecho que no pasó desapercibido para Enrique Molina.

"el señor Presidente ha sido sorprendido con una nueva comunicación firmada por los tres miembros del jurado en que declaran que las mejores de todas las composiciones que se han presentado al concurso son los dos himnos firmados con el seudónimo de Mario - Netti (Próspero Bisquertt); y declaran, en seguida, que dan este juicio, manteniendo su opinión anterior "de que la trascendencia del asunto les impide aconsejar la adopción de ninguna de las composiciones presentadas a su discernimiento". Como se ve, dice el señor Molina, este

${ }_{48}^{48}$ ACS-UdeC. Libro 5, folio 105. Sesión en 22 de Noviembre de 1939.

49 lbíd. 
informe no implica una aceptación franca. Con tal declaración se contradicen los señores miembros del jurado quienes verbalmente expresaron al señor Rector que los himnos del señor Bisquertt eran aceptables, salvo un pequeño tropezón que se podría arreglar. La situación es un poco delicada. No se puede abrir nuevo concurso. Se pidió a los mejores compositores de Chile, por lista obtenida de la Facultad de Bellas Artes, que presentaron a este certamen.

El consejero señor Mora, dice que el señor Bisquertt es una de las grandes figuras de la música chilena, por lo cual se inclina en favor de su trabajo.

El Consejero señor Parada, manifiesta que el Consejo no está tan obligado a aceptar el dictamen del jurado como para no poder resolver por si solo en este asunto. Se acordó premiar estos dos himnos de que el autor es don Próspero Bisquertt y someterlos a una nueva revisión del propio compositor de ellos". ${ }^{50}$

Es interesante notar, aunque esto puede resultar de la redacción del Secretario, que en el acta de noviembre se habla claramente de "el himno", en singular, mientras que en la de diciembre las menciones figuran en plural. No hay duda de que la disposición fue, desde el inicio, premiar dos composiciones. Pero no queda suficientemente claro si la intención de otorgar el doble premio a Bisquertt fue considerada desde siempre por el jurado. Al menos, eso sí, nunca evidenciaron una intención de premiar a alguien más.

Finalmente, el 22 de diciembre se despachó el monto del premio ${ }^{51}$. Con dos correcciones de por medio, las versiones definitivas fueron premiadas, aceptadas como oficiales por la Universidad de Concepción y publicadas por Editorial Casa Amarilla en 1940, tituladas Himno de la Universidad de Concepción e Himno $N^{\circ} 2$ de la Universidad de Concepción (Imagen 3), con los poemas de Silva y Gamonal respectivamente.

A fines de 1943 se vuelve a recurrir a Bisquertt para comisionarle que elabore nuevas versiones, esta vez para coro. Detrás de la solicitud estaban las condicionantes de una realidad material. La universidad no contaba todavía con una repartición dedicada a la música; no había cantantes, pianistas ni menos una orquesta. Tampoco se contaba con elencos corales estables, profesionales o aficionados, que pudieran participar de sus ceremonias por compromiso institucional. Para todo ello se requería todavía de colaboraciones externas.

Consecuentemente, no hay noticia de que los himnos ganadores se hayan ejecutado durante los cuatro años posteriores a su oficialización. Es plausible pensar que existió una presentación en sociedad de las piezas y una que otra audición en ceremonias oficiales en la medida que existiese un piano en el recinto que permitiese su ejecución. Sabemos, en cambio, que las versiones corales fueron interpretadas por primera vez el día 23 de abril de 1944, por

\footnotetext{
${ }^{50}$ ACS, UdeC. Libro 5, folios 110-111. Sesión en 20 de Diciembre de 1939.

${ }^{51}$ AC, UdeC. Exp. 81-370. Carta de Enrique Molina a Próspero Bisquertt, 22 de diciembre de 1939.
} 
los Coros Polifónicos de la Corporación Sinfónica de Concepción, dirigidos por Arturo Medina, durante la inauguración de la Casa del Deporte, actividad con que se dio término a la celebración de las bodas de plata de la Universidad de Concepción.

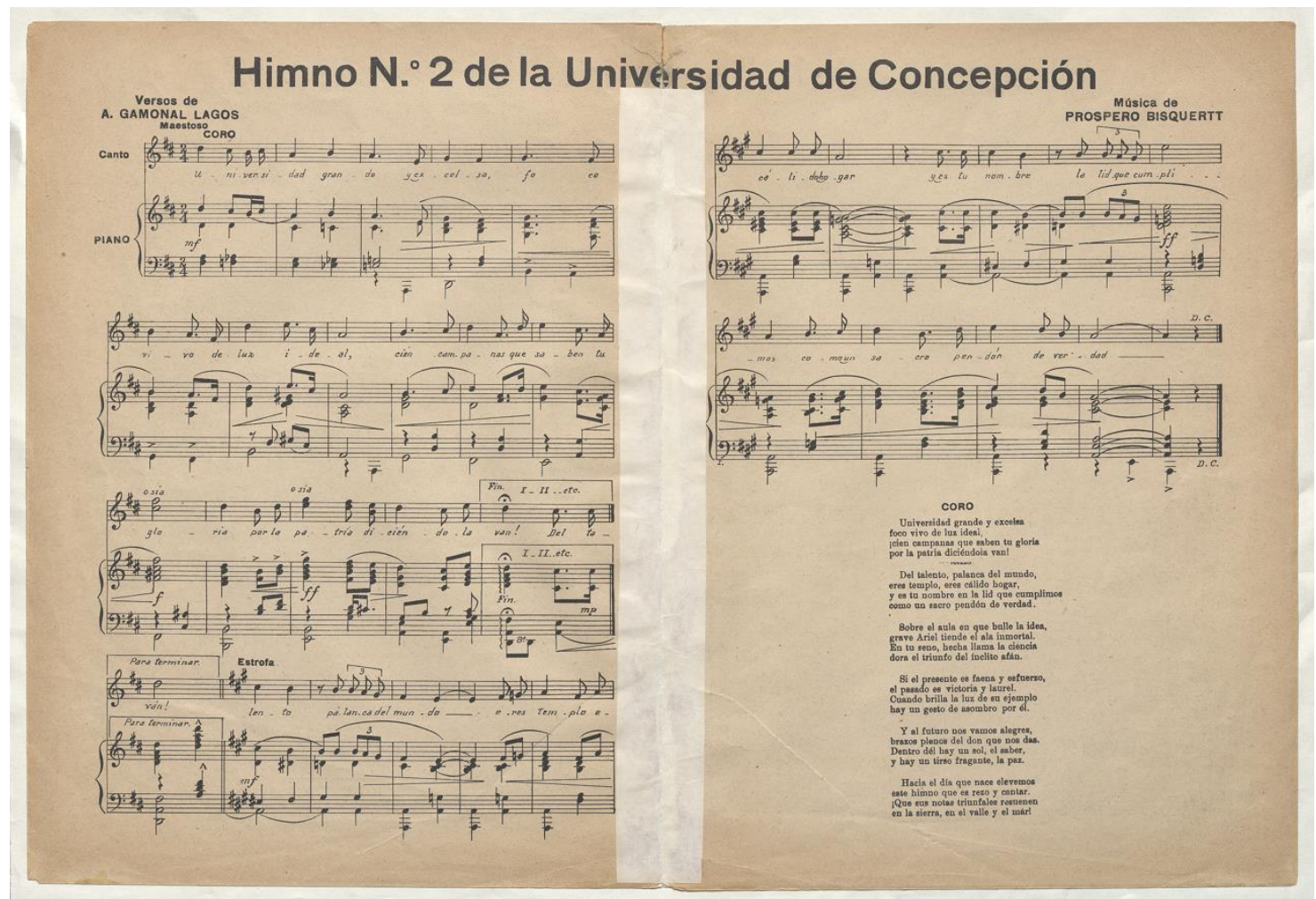

Imagen 3. Himno de la Universidad de Concepción. Letra, Víctor Domingo Silva; Música, Próspero Bisquertt Prado. Santiago, Casa Amarilla, 1940. Fuente: Archivo de Música, Biblioteca Nacional.

\section{La intriga hímnica frente al escenario nacional.}

Expuesto el tortuoso proceso para conseguir los primeros himnos de la Universidad de Concepción, será necesario situarnos en el escenario de la música nacional para entender, de ida y vuelta, los alcances extra-locales de las decisiones institucionales.

Entre las décadas de 1920 y 1940 la música chilena atravesó un "proceso refundacional". Se trató de un recambio de la institucionalidad musical que hizo parte de una cambio amplio y transversal en América Latina, caracterizado por la "creación de instituciones públicas de alcance nacional impulsadas por figuras de un fuerte liderazgo aglutinador" 52 y materializado

\footnotetext{
52 Merino, Luis y Garrido, Julio. 2018. “La crisis institucional de la Universidad de Chile y la circulación, preservación, recepción y valoración de la música sinfónica de los compositores chilenos: una propuesta teórico-metodológica", en Resonancias, №42, Santiago, p. 80.
} 
en la "creación de instancias y mecanismos institucionales cuyo objetivo prioritario fue promover de manera vigorosa la formación, el cultivo y la comunicación de la obra de los compositores del país y de los músicos chilenos en general ${ }^{\prime 53}$ con miras a la instalación de un paradigma monoinstitucional ${ }^{54}$.

En Chile, este proceso se inauguró con la fundación de la Sociedad Bach en 1924, conformada por un grupo de ciudadanos influyentes de la capital. Fue encabezado por el abogado Domingo Santa Cruz Wilson y tuvo como puntos clave la reforma del Conservatorio Nacional en 1928, con su subsecuente incorporación a la Facultad de Bellas Artes de la Universidad de Chile en 1929, y la fundación del Instituto de Extensión Musical (IEM) en 1940. Este último fue una entidad estatal que, al alero de la Universidad de Chile, tuvo la potestad de administrar toda actividad musical considerada oficial en el país, canalizando sus acciones a través de diversos organismos como la Orquesta Sinfónica de Chile (1941), el Instituto de Investigaciones Folklóricas (1943), la Revista Musical Chilena (1945), el Ballet Nacional Chileno (1945), entre otros ${ }^{55}$.

El proceso es correlativo al impulso modernizador que experimentaba el país, y que en este caso transformó "a la música y las artes en Chile en un medio universitario, controlado por el Estado desde el punto de vista económico y por los compositores de la Universidad de Chile, desde el punto de vista administrativo" ${ }^{56}$. Las implicancias, por supuesto, no se agotan en lo referente a la gestión. El Instituto de Extensión Musical se instituyó como un espacio de poder con la capacidad para legitimar (o no) toda actividad musical. Su influencia fue determinante sobre los discursos estético-ideológicos y las tendencias estilísticas que predominaron en el país ${ }^{57}$, el posicionamiento de los músicos en la escena nacional ${ }^{58}$ y las construcciones locales de institucionalidad musical ${ }^{59}$.

Establecido el modelo, la música docta chilena se inclinó hacia los preceptos del iluminismo romántico, con sus ideales del compositor -el genio creador-, la obra de arte y la música absoluta $^{60}$ en la cúspide de la pirámide. Dentro de ese esquema, las expresiones de tradición

\footnotetext{
53 lbid., p. 81.

54 lbíd., p. 82.

55 Vera, Fernanda. 2015. ¿Músicos sin pasado? Construcción conceptual en la historiografía musical chilena, Santiago, Universidad de Chile, Tesis para optar al grado de Magister en Artes con mención en Musicología, pp. 6-7 56 José Manuel Izquierdo en Doniez, Roberto. 2011. Palabra de Soro, Valparaíso, Editorial Altazor, p. 15.

${ }^{57}$ Ver Peña, María Pilar y Poveda, Juan Carlos 2010. Alfonso Leng. Música modernidad y chilenidad a comienzos del siglo XX, Santiago, Autoedición con financiamiento del Fondo de Fomento de la Música Nacional, pp. 51-85

58 Ver Vera, F. 2015. ¿Músicos sin pasado...?

59 Ver Masquiarán, Nicolás. 2011. La construcción de la institucionalidad musical en Concepción, 1934-1963, Santiago, Universidad de Chile, Tesis para optar al grado de Magister en Artes con mención en Musicología.

${ }^{60} \mathrm{El}$ concepto música absoluta refiere a un problema estético que presupone la posibilidad de una música como fin en sí mismo, no supeditada a otros tipos de expresión o representación, como en la canción, la ópera, la música programática o requerimientos de expresión emocional. En el imaginario iluminista-romántico, la música absoluta
} 
germánica y filiación modernista-neoclásica -señeramente llamadas "universalistas"61_ eran preferibles por sobre cualquier otra tendencia coexistente, muy especialmente por sobre la ópera y el italianismo ${ }^{62}$.

Aunque la musicología más reciente ha sido crítica y deconstructiva respecto del relato canónico sobre la música nacional ${ }^{63}$, la "historia oficial" ${ }^{64}$, que también encuentra eco en trabajos más actuales ${ }^{65}$, presenta a los compositores como figuras casi exclusivas. Sumando, el prólogo de Domingo Santa Cruz para Los orígenes del arte musical en Chile es taxativo en negar cualquier proceso histórico previo al referirse a los compositores nacionales de la primera mitad del siglo XX como "músicos que vivíamos sin pasado" ${ }^{66}$. Publicaciones anteriores ${ }^{67}$, sin embargo, demuestran la existencia de un nutrido ambiente musical previo al proceso de modernización y revelan así el pasado de aquellos músicos que supuestamente carecían de él. Además, prestaban similar atención a intérpretes y compositores, y daban cuenta de algunos educadores.

Por otro lado, en estos relatos canónicos se omitió o denostó a cualquiera que demostrara demasiada proximidad con la música decimonónica o el modelo formativo del antiguo Conservatorio Nacional. En palabras del musicólogo José Manuel Izquierdo,

"Cualquiera que lea los textos de Domingo Santa Cruz, Vicente Salas Viú, Samuel Claro y Roberto Escobar sobre la música chilena encontrará que estos creadores, si no anulados, son ridiculizados, ignorados o referidos como anécdotas históricas. Cualquiera que revise, en cambio, la prensa anterior a 1928, verá que esto no es así y, muy por el contrario, la música en Chile no es una de "músicos sin pasado", sino de una constante evolución -dudaría aquí del concepto de progreso-, marcada por las diversas influencias propias de un país que

se supone por encima de cualquier otra forma de expresión musical. Cf. Sadie, Stanley (ed.). 1980. Absolute Music. The New Grove Dictionary of Music and Musicians, Londres, Macmilan Publishers, I, pp. 26-27.

${ }^{61}$ Claro, Samuel y Urrutia, Jorge. 1973. Historia de la música en Chile, Santiago, Orbe.

62 Peña, María Pilar y Poveda, Juan Carlos 2010. Alfonso Leng..., pp. 58-69.

63 Podemos considerar aquí, entre los que abordan el tema de forma más directa, a Vera, F. 2015. ¿Músicos sin pasado...?, Peña, M. y Poveda, J. C. 2010. Alfonso Leng... e Izquierdo José Manuel. 2011. "Aproximación a una recuperación histórica: compositores excluidos, músicas perdidas, transiciones estilísticas y descripciones sinfónicas a comienzos del siglo XX", en Resonancias, №28, Santiago, pp. 33-47.

${ }^{64}$ Acá se consideran generalmente los trabajos de Claro, S. y Urrutia, J. 1973. Historia de la música..., Pereira S., E. 1941. Los orígenes del arte musical en Chile, Santiago, Publicaciones de la Universidad de Chile; Salas Viú, Vicente. 1952. La creación musical en Chile, 1900-1951, Santiago, Ediciones de la Universidad de Chile.

65 Díaz, Rafael y González, Juan Pablo. 2011. Cantus firmus: mito y narrativa de la música chilena de arte del siglo $X X$, Santiago, Editorial Amapola.

66 Pereira, Eugenio. 1941. Los orígenes..., p. xii. La idea fue suficientemente exitosa como para ser refrendada en el título de un trabajo bastante posterior sobre los compositores chilenos: Escobar, Roberto. 1971. Músicos sin pasado. Composición y compositores de Chile, Barcelona, Editorial Pomaire.

67 Sandoval, Luis. 1911. Reseña Histórica del conservatorio Nacional de Música y Declamación 1840 a 1911, Santiago, Imprenta Gutemberg y Uzcátegui G., Emilio. 1917. Músicos chilenos contemporáneos (Datos biográficos $e$ impresiones sobre sus obras), Santiago, Imprenta y encuadernación América. 
confunde sus propias miradas con las del extranjero, el interior oculto y la negación constante de sí mismo." 68

En lo práctico, el grado de adherencia al proyecto modernizador definió además grados de participación en los espacios de poder, manifiesto en situaciones tan variadas como articulación de círculos sociales, consideración en los programas de concierto, adjudicación de financiamientos, puestos de trabajo o asignación de cargos administrativos. Un ejemplo de ello que compete a nuestro caso es la fundación, en 1936, de la Asociación Nacional de Compositores, iniciativa animada por Domingo Santa Cruz como alternativa a la Sociedad de Compositores de Chile ${ }^{69}$, que existía desde 1920 y donde se congregaban los detractores de su modelo. En términos más directos, "surgió para contrapesar, y con el tiempo reemplazar a la $\mathrm{SCCH}^{\prime 70}$.

\section{Los concursantes}

Volvamos ahora a los sujetos, concursantes y jurados, para revisar el efecto que todo lo anterior pudo tener sobre la elección del Himno de la Universidad de Concepción. Héctor Melo Gorigoytía (1889- ?) $)^{71}$, fue un discípulo de Enrique Soro escuetamente mencionado por los historiadores. Se le reconoce "una fina y equilibrada personalidad que muy pronto le hizo figurar en la música moderna [...] dentro de las tendencias derivadas del impresionismo"72. La reseña de Rengifo es mucho más encomiosa. Lo destaca como una joven promesa de la música nacional "que marcha hacia una franca evolución artística" ${ }^{73}$, ganador de algunos premios uno de ellos otorgado por la Sociedad Bach-y cuyo "gran temperamento de artista, su ciencia lo hacen colocarse entre los más grandes compositores chilenos"74. Así y todo, su producción parece haberse detenido hacia inicios de la década de 1940, quizá por haberse volcado hacia su profesión de ingeniero en minas, como sugiere su entrada en el Diccionario Biográfico de Chile $^{75}$ y las referencias de Santa Cruz en sus memorias. En todo caso, aparece vinculado a la

\footnotetext{
68 Doniez.. 2011. Palabra de Soro, p. 16.

${ }^{69}$ En sus memorias (Santa Cruz W., Domingo. 2008. Mi vida en la música. Santiago, Universidad Católica de Chile), se refiere a la SCCH y la Sociedad Nacional de Bellas Artes como "las dos entidades tradicionalmente contrarias a nosotros" (Ibíd., p. 865), mientras que a la ANC "de inmediato se adhirieron los creadores de mayor prestigio que había en el país, con excepción de Enrique Soro que militaría aún por varios años en el campo opuesto" (Ibíd., p. 475).

70 Guerra, Cristián. 2019. "La procesión de Próspero Bisquertt: instituciones y mediaciones en torno a una obra chilena en proceso de canonización y la trayectoria de su compositor", Resonancias, 44, p. 110.

${ }^{71}$ En otras fuentes figura como Melo Gorigoitía. Desconocemos su fecha de deceso, pero por la biografía publicada en Historia de la música en Chile debió ser posterior a 1973.

72 Claro, S. y Urrutia, J. 1973. Historia de la música..., p. 159.

73 Rengifo, Javier. 1928. "Los compositores chilenos", Zig Zag, 28 de abril, p.81

74 lbíd.

${ }^{75}$ S/A. 1953. Diccionario Biográfico de Chile, 9a Edición, Santiago, Empresa Periodística de Chile, pp. 797-798.
} 
ANC y el $\mathrm{IEM}^{76}$, y su música continuó siendo programada hasta principios de la década siguiente.

Javier Rengifo Gallardo (1884-1958) ${ }^{77}$ es un excelente caso para graficar la afirmación de José Manuel Izquierdo citada arriba. Con él los musicólogo-historiadores son especialmente lapidarios. Si bien lo destacan como un gran improvisador, esta es una destreza cada vez menos valorada entre los músicos de academia por su distanciamiento con la creación como actividad intelectual y su sospechosa proximidad con las prácticas populares. Se le retrata como un "autor de obras populacheras de éxito fácil", un compositor "víctima de su facilidad", cuya música cuenta con escasos fundamentos técnicos, "casi como improvisaciones" entre las que reina "la anarquía de los géneros más opuestos" y es "casi imposible establecer un orden, incluso determinar características generales" ${ }^{78}$. Aunque se valora su intento de renovarse estilísticamente en obras tardías, asociado a la utilización de recursos modernistas, se le atribuye en general un temperamento romántico comparable al de Enrique Soro o, lo que es lo mismo decir, anacrónico y obsoleto. Adicionalmente, en sus intentos como director de orquesta, Santa Cruz lo ridiculiza refiriéndose a él como un "talento verdadero, pero en bruto, [que] no pasaba de un gesticulador inútil y teatral, y más de entusiasta aspirante al pupitre"79. Un dato último, no menos importante, llegó a ser presidente de la SCCH hacia 1928.

Enrique Soro (1884-1954) ha sido reconocido como uno de los compositores más importantes para nuestro país, y sin duda fue el más influyente durante el primer cuarto del siglo XX. Sus reseñas en los libros de historia tienden a ocupar un espacio significativamente mayor que las de otros compositores. Sin embargo, fue la víctima propiciatoria del proceso de recambio institucional. Además de su ascendencia italiana y su formación en el Conservatorio de Milán ${ }^{80}$, había sido Director del Conservatorio Nacional hasta 1928, año en que fue arbitrariamente removido de su cargo para allanar terreno a la reforma, gracias a gestiones realizadas a nivel gubernamental ${ }^{81}$. A partir de entonces se le mantuvo a raya de los espacios de poder. Su retorno a la esfera administrativa ocurre recién después de 1940, cuando frente a

\footnotetext{
76 Santa Cruz, D. 2008. Mi vida en la música..., p. 475 y p. 816, respectivamente.

77 En el Diccionario Biográfico de Chile (1953, p. 1030) y la "Necrología" publicada en Revista Musical Chilena con motivo de su deceso, de más fácil acceso público, aparece como año de nacimiento 1879 . Sin embargo, la mayoría de las otras fuentes disponibles declaran 1884.

78 Salas Viú, Vicente. 1952. La creación musical en Chile..., pp. 351-354.

79 Santa Cruz, Domingo. 2008. Mi vida en la música..., p. 579.

80 Sobre este punto, cabe ahondar en la declarada simpatía entre núcleo refundacional y la disposición germanizante. Son años todavía cercanos a la tristemente célebre tesis de Nicolás Palacios sobre el chileno gótico (Raza Chilena, 1904) y la influencia del "embrujo alemán" (Collier, Simon y Satter, William. 1998. Historia de Chile 1808-1994, Cambridge, Cambridge University Press, pp. 163-165). En lo referente a la refundación de la institucionalidad musical, se observa una disposición racializadora que prioriza la tradición germánica neo-clásica, llamada "universalista", por sobre cualquier otra, especialmente la italiana. (Masquiarán D., Nicolás. 2018. "A través del espejo. Proyecciones contemporáneas al caso Soro". Ámbito Sonoro, 5, pp. 23-35.)

${ }^{81}$ Pérez, Carlos. 2012. En busca del piano perdido (Documental).
} 
los hechos consumados y legalmente sancionados su presencia resultaba inofensiva. En lo artístico, si bien las apreciaciones sobre su oficio como compositor, director y pianista son casi siempre elogiosas, es común encontrar en los textos canónicos sutiles comentarios de descrédito, como el siguiente, escrito bien entrado el siglo XX: "Probablemente si Soro hubiera producido sus obras durante el siglo XIX, nos enorgulleceríamos hoy de contar en nuestras filas con un músico de proyecciones geniales" ${ }^{\prime 2}$.

Próspero Bisquertt fue un músico más o menos constante en su filiación estética, donde se le reconoce hasta el día de hoy como un compositor "de carácter nacionalista unas veces, descriptivo y poemático otras"83. Es decir, ni "universalista" ni aspirante a la música absoluta. No es de extrañar entonces que, pese a gozar de reconocimiento, sus reseñas puedan aparecer acompañadas de comentarios como "se mantiene en un sentimentalismo superficial o cae en lo pintoresco, siempre creando una música de hermosa realización y transparencia orquestal [...] que resalta tanto como lo débil de su proceso constructivo"84. Así y todo, junto a Soro y a diferencia de los otros concursantes, su nombre ha pasado a formar parte del canon de la música docta chilena gracias a la obra Procesión del Cristo de Mayo (1930) ${ }^{85}$.

Pero a pesar de su persistencia estilística, las filiaciones sociales e institucionales de Próspero Bisquertt fueron algo más pasajeras. Mientras que en 1920 figura como parte del primer Directorio de la $\mathrm{SCCH}$, parece haberse abanderado por el proyecto refundacional luego de "integrar, junto con Enrique Soro, Domingo Santa Cruz y otros personajes clave del mundo musical, una comisión encabezada por el ministro y destinada a diseñar una reforma de la enseñanza musical en Chile" ${ }^{\prime 86}$, iniciativa que condujo a la reforma del Conservatorio Nacional. Ahí se inaugura la que parece ser la etapa más favorable de su carrera. Al momento en que se realizó el concurso por el Himno de la Universidad de Concepción, la fundación del IEM estaba próxima a sancionarse ${ }^{87}$. A poco andar Bisquertt fue elegido para el cargo de Administrador dentro de una terna propuesta por Santa Cruz, en reconocimiento a su idoneidad, dada su experiencia como profesional (ingeniero), compositor e inspector de Impuestos Internos ${ }^{88}$.

Dos comentarios sobre el IEM antes de pasar al siguiente punto. Primero, en un simbólico gesto de descentralización el directorio contemplaba en su constitución al rector de la Universidad de Concepción. Por supuesto, dada la periodicidad de las reuniones y las dificultades inherentes, Enrique Molina Garmendia nunca llegó a participar directamente. En

\footnotetext{
82 Claro, Samuel. 1969. Panorama de la música contemporánea en Chile. (Colección de Ensayos N 16), Santiago, Facultad de Artes de la Universidad de Chile, p. 6. Cursivas añadidas por el autor.

${ }^{83}$ Salas Viú, V. 1952. La creación musical..., reducción digital.

84 lbíd.

85 Ver Díaz, R. y González, J. P. 2011. Cantus firmus...

${ }^{86}$ Guerra, Cristián. 2019. “La procesión de Próspero Bisquertt...", p. 107.

${ }^{87} \mathrm{El}$ IEM se funda oficialmente con la ley 6.696, del 11 octubre de 1940.

${ }^{88}$ Actas del IEM. 1940-41. Acta Na 4, 19 de octubre, folio № 22.
} 
cambio, delegó en Benjamín Claro Velasco, diputado por Santiago que más tarde asistiría a la inauguración de la Casa del Deporte investido como Ministro de Educación. Lo sabemos cercano a Santa Cruz por las menciones en sus memorias, donde aparece vinculado a la Sociedad Bach y, por ende, como un adherente a la reforma del Conservatorio Nacional ${ }^{89}$. Por lo visto, Concepción no era ajena a las maquinaciones que se realizaban en Santiago respecto de la construcción de los espacios institucionales, pero con una presencia más nominal que activa en lo referente a atribuciones y tareas administrativas. Segundo, el Secretario del IEM en su primera época fue nada menos que Vicente Salas Viú, cronista oficial y descarnado juez de los músicos nacionales que ya mencionamos antes.

\section{Los jurados}

Para fines de 1939, al mismo tiempo que se realizaba el concurso y se resolvían los últimos detalles para la fundación del IEM, Arturo Medina McKey era Director de la Corporación Sinfónica de Concepción, de sus Coros Polifónicos y probablemente la mayor autoridad musical de su ciudad. Desde esa posición intentaba ganarse la avenencia de esta élite capitalina. El hecho se constata en los diversos acercamientos que se habían producido en los últimos meses y que habían magnificado el reconocimiento de su elogiado conjunto. Medina, buscaba vincular su institución al poder central, asegurando así su autonomía respecto del influjo de la Universidad sobre el ambiente cultural local. Esta vinculación condujo a que, frente a la falta de un conjunto coral "nacional", el suyo fuera considerado para acompañar a la Orquesta Sinfónica de Chile en sus temporadas regulares en Santiago y sus giras hacia el sur del país ${ }^{90}$.

De Roberto Ide Pereira poco sabemos en lo referente a su carrera, excepto que continuó enseñando música en Concepción hasta por lo menos la década de 1960. Alfonso Izzo por su parte, que había enseñado en el Conservatorio Enrique Soro de Concepción, figura en algunos números tempranos de la Revista Musical Chilena como representante de la Orquesta Sinfónica de Chile ante el IEM, de modo que sus filiaciones quedan en evidencia. Fue justamente Izzo quien, según la prensa, tuvo la última palabra respecto de los himnos ganadores ${ }^{91}$.

\section{Hechos y conjeturas sobre el concurso}

Desde un punto de vista estético, ninguno de los aspirantes aparecía como un candidato ideal por adherencia a la tendencia predominante -aunque sería errado afirmar que ninguno de ellos

\footnotetext{
89 "Benjamín Claro Velasco [era] antiguo amigo y partícipe de la sociedad Bach, en cuyo coro aparece retratado al ejecutarse el Oratorio de Navidad en 1925". Santa Cruz, D. 2008. Mi vida en la música..., p. 576.

90 En Masquiarán D., Nicolás. 2011. "iOtra! ¡Otra! Luchas y tensiones en la oficialización de las músicas locales: el caso de Concepción", Resonancias, 28, pp. 19-32, se evidencia cómo el vínculo entre Medina y Santa Cruz sirvió de plataforma para favorecer la recepción del conjunto coral penquista en Santiago.

91 "Ha quedado reducida la elección solo a cuatro himnos, de entre los cuales elegirá el conocido músico, señor Alfonso Izzo el que más convenga a la música adoptada". La Patria, 9 de noviembre de 1939, p. 7.
} 
exploró en recursos modernistas-. Como ya se ha dicho, Soro era considerado representante de un romanticismo anacrónico y del denostado estilo italiano, lo mismo que Rengifo, que además había sido formado en el Conservatorio Nacional ${ }^{92}$. Melo había sido discípulo de Soro, aunque la historia oficial le reconoce una redentora inclinación por el modernismo y el impresionismo. A Bisquertt, por su parte, se le intenta perfilar como autodidacta, diluyendo así la mácula de haber sido formado por músicos del conservatorio ${ }^{93}$. Estilísticamente, se le sitúa siempre entre los nacionalistas, que en Chile equivale a una estética impresionista matizada por materiales rítmico-melódicos extraídos de -o inspirados en-el folklore.

Todas estas atribuciones se podían traducir en un prejuicio sobre el trabajo creativo, de modo que, si algún compositor indagaba en otras tendencias, se solía interpretar como una exploración o superposición de recursos "ajenos" sobre una base predefinida. Prueba de ello pueden darla algunos de los comentarios presentados antes sobre cada compositor.

$\mathrm{Si}$ bien ningún aspirante adhiere categóricamente al referido "universalismo", la jerarquización estética vigente sitúa al nacionalismo por sobre el romanticismo tardío de Soro, sumamente apto para los escenarios de concierto siempre que venga rubricado por un compositor consagrado, ya fallecido y preferentemente germánico -Brahms y Wagner son bienvenidos-, mas no tanto para las nuevas propuestas compositivas de músicos con su sangre aun circulando. Otros estilos de vanguardia más avanzada, aunque ya están siendo explorados por algunos creadores, no habían llegado a tener una repercusión significativa en el país.

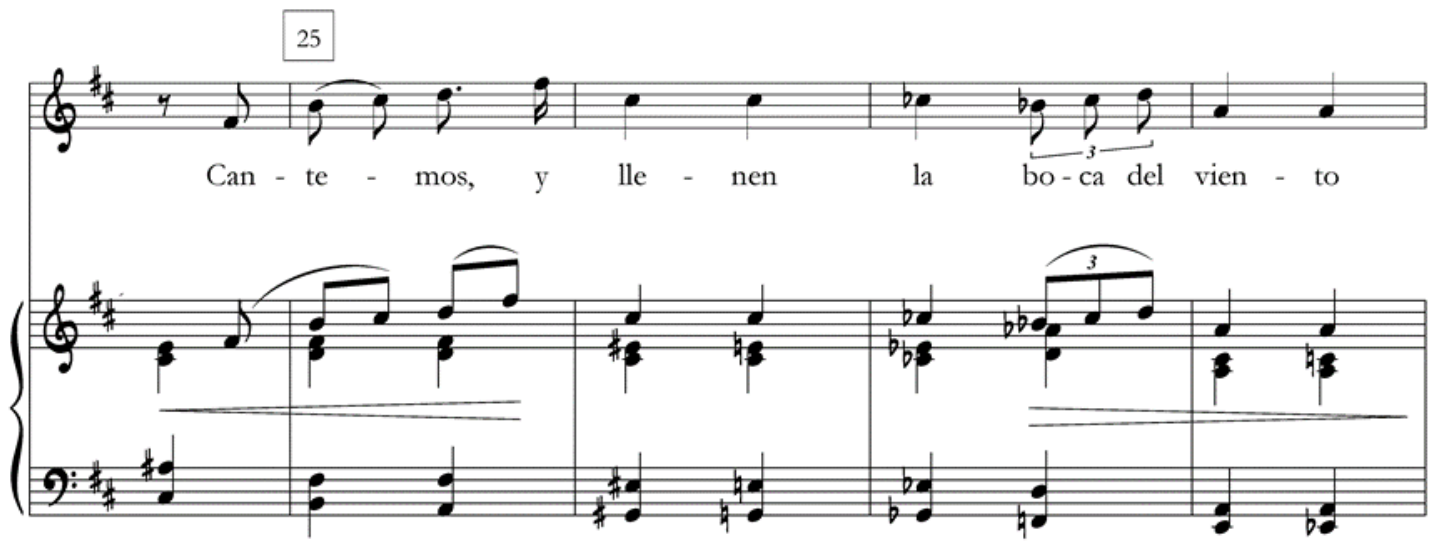

Imagen 4. "Himno de la Universidad de Concepción", de Próspero Bisquertt. Compases alzar 25 al 28. Transcripción de Nicolás Masquiarán Díaz según edición de Casa Amarilla (1940).

En todo caso, al revisar las partituras disponibles, encontramos que la composición de Bisquertt está bien lejos del impresionismo, poco funcional para un himno institucional que

\footnotetext{
92 Salas Viú, V. 1952. La creación musical..., reducción digital.

93 Guerra, C. 2019. "La procesión de Próspero Bisquertt...", p. 104.
} 
idealmente debe poseer una base armónica tonal suficientemente clara y una melodía simple, recordable y reproducible por una voz no entrenada, que facilite el canto colectivo. En cambio, se atreve a jugar con recursos más próximos al romanticismo tardío y el expresionismo germánicos, por cierto-, como los cromatismos que aparecen en la sección central de su Himno de la Universidad de Concepción (Imagen 4), que se vuelven aún más complejos de entonar en la adaptación coral.

Por otro lado, llama la atención que, frente a la solicitud de componer "para orquesta o una reducción para piano fácilmente instrumentable", en las partituras de Bisquertt no se evidencia una intención orquestal detrás de sus piezas, que bien pueden ser asimiladas como canciones para voz y piano. Por supuesto, todo es susceptible de ser orquestado. Pero ocurre muy diferente con Soro, que desde sus primeros compases evidencia las posibilidades orquestales. Especialmente aquella presentada bajo el seudónimo de Ars et Labor sobre el texto de Gamonal, con una densidad sonora y armónica que la hace sumamente compleja de abordar al piano si no es por un intérprete profesional (Imagen 5). Un atrevimiento que podría haber sido puesto bajo sospecha por "operático", aun cuando Soro jamás llegó a componer una ópera.
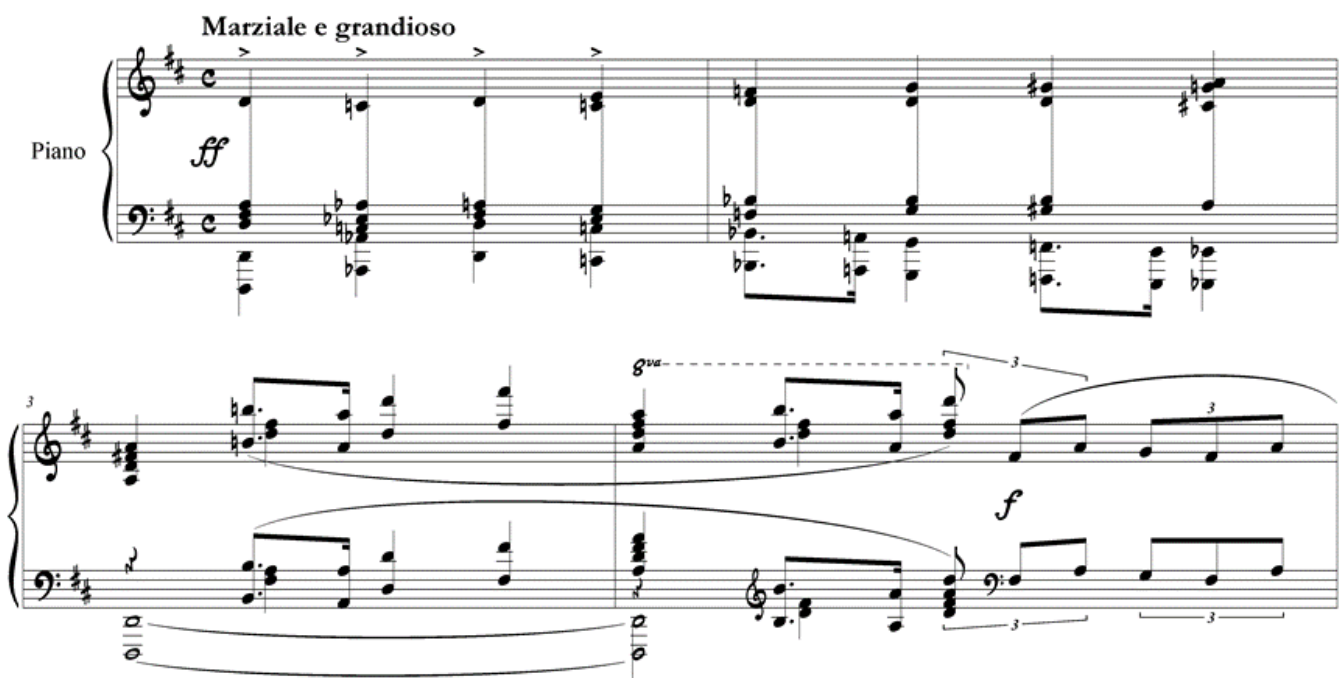

Imagen 5. Himno de la Universidad de Concepción, de Ars et Labor (Enrique Soro). Compases 1 al 4. Transcripción de Nicolás Masquiarán Díaz (Autorizado) según manuscrito conservado en Archivo Enrique Soro.

Dejo hasta acá las apreciaciones técnicas, pues no es la intención de este trabajo emitir un juicio valorativo sobre las propuestas. Tampoco disponemos de la totalidad de las partituras 
presentadas a concurso, ni conocemos los criterios que pudo aplicar el jurado. Sí son claros, en cambio, los prejuicios de turno sobre las tendencias estilísticas vigentes en el país.

En lo social, tanto Rengifo como Soro figuran como abiertos opositores al proyecto santacruciano. Por ende, en una posición marginal dentro de la institucionalidad emergente. En particular Soro, por su amplio prestigio internacional, todavía era percibido como un vigoroso agente de resistencia. Melo, aparece relativamente distante al círculo social hegemónico en comparación con Bisquertt que, como ya hemos dicho, por aquellos años se encontraba estrechamente vinculado al punto de ser considerado para formar parte del Directorio del IEM.

Aunque sería sumamente complejo encontrar una prueba definitiva, es razonable suponer que tanto Izzo como Medina pudieron haber influido en el resultado apoyando una decisión que, al margen de cualquier mérito técnico-musical, les permitiera congraciarse con las intenciones del IEM de modo que resultara favorable a sus propios intereses. El uno acabó empleado por la Orquesta Sinfónica de Chile; el otro, consiguió más tarde patrocinio, financiamiento y plataforma para proyectar al que sería reconocido por décadas como el conjunto coral de mayor excelencia en el país, posición que como mínimo hubiese sido más dificultosa de alcanzar con una gestión realizada únicamente desde la provincia.

Si el vínculo entre Medina y Santa Cruz era tan estrecho, lo confirma la ley 9.574 de 1950, promovida por este último, que asignó a los coros polifónicos una subvención permanente del Estado en términos semejantes a los que procuraban el financiamiento del IEM, y que allanó el camino al posicionamiento de la Corporación Sinfónica como organismo cultural líder en la zona sur. La bonanza duró hasta la derogación de la ley en 1973, al mismo tiempo que fue disuelto el IEM ${ }^{94}$.

Si eran posibles maquinaciones tales como obviar protocolos con tal de favorecer intereses personales, tenemos conocimiento de que Medina se coló en la comisión que confirió el Premio Nacional de Arte a Domingo Santa Cruz en 1951. El reconocimiento debió ser impugnado por la Contraloría General de la República ${ }^{95}$. No es de extrañar, entonces, que el nombre de Próspero Bisquertt Prado ya estuviera en boca del jurado antes de definir el premio. No debió haber sido diferente con los otros concursantes. $Y$, en todo caso, como alguna vez me expresó un compositor nacional, los concursos ciegos nunca son tan ciegos... menos en tiempos de grafía manuscrita.

\footnotetext{
${ }_{94}^{94}$ Masquiarán, N. 2011. La construcción de la institucionalidad... y Masquiarán, N. 2011. jOtra! iOtra!

${ }^{95}$ Masquiarán, N. 2011. La construcción de la institucionalidad..., p. 207.
} 


\section{Hacia un himno definitivo}

Señeramente, la prensa publicada para la inauguración de la Casa del Deporte nos dice que, habiéndose cantado los himnos universitarios y el himno nacional, "este último fue coreado por todos los asistentes" ${ }^{\prime 96}$. Pero de los institucionales, ni hablar. En efecto, las piezas de Bisquertt no trascendieron. Un destino que se le puede atribuir a dos factores de índole social, sin descartar que existan otras causas probables.

El primero se relaciona con los procedimientos para conseguir las obras. Como se observa en las secciones anteriores, mientras que la convocatoria al poema fue abierta, alentó la participación ciudadana y generó expectativas entre la comunidad. Con la música en cambio, se dio en términos bastante más herméticos: invitaciones directas y escasa difusión en la prensa en comparación con el proceso anterior. Las menciones más significativas aparecen en torno a la fecha de entrega del premio, pero no se observa un seguimiento periódico del concurso como ocurriera con los poemas. Lo que pudo haberse avanzado en la primera instancia en términos de involucramiento con la comunidad, se retrocedió en la segunda. Más aún si consideramos que se había hecho manifiesto el interés de esa comunidad por proveer también el arreglo musical.

Segundo -y probablemente lo más determinante-, sin los medios disponibles para divulgar sistemáticamente los himnos universitarios hacia la comunidad, ambos cantos debieron ir cayendo en el olvido. En otros términos, las condiciones no contribuyeron a la escucha social y la apropiación de los himnos como representaciones de la identidad institucional.

A principios de la década de 1950, un joven colaborador de Arturo Medina llamado Wilfried Junge Eskuche, fue encomendado por la Federación de Estudiantes para formar y dirigir una agrupación coral que aspirara a convertirse en el coro institucional. El proyecto fracasó. Sin embargo, fue receptora de un particular regalo de su director: una nueva versión del Himno de la Universidad de Concepción, que recuperaba el texto de Víctor Domingo Silva, iniciando con la potente frase "por el desarrollo libre del espíritu"97.

En pleno auge del movimiento coral nacional, esta versión espuria parece haber encontrado una mayor aprobación por parte de la comunidad. En la página 19 de una revista denominada Renovación $^{98}$, de 1956, se encuentra impresa una transcripción de la melodía señalada como "obsequio" y con la indicación "para recortar" (Imagen 6). Un gesto bastante sugestivo respecto de las expectativas de trascendencia puestas sobre esta nueva melodía, o la aprobación que ya había llegado a obtener. En todo caso, la música aparece como anónima.

\footnotetext{
${ }^{96}$ BC? El Sur, 24 de abril de 1944, p. 10.

97 Masquiarán, N. 2011. La construcción de la institucionalidad..., p. 189. Existen discrepancias respecto de las fechas, pero considerando la prensa, los hechos ocurrieron más probablemente en 1951.

98 BC, UdeC, AVSCH-SU-H-22. No existen mayores antecedentes sobre la revista, pero la humorada publicada en el reverso respecto de la elección de rector, además de datarla, sugiere su procedencia local.
} 
Si la escucha social e identificación eran los factores clave para la penetración del himno como símbolo, en la década de 1950 se produce un cambio en las condiciones que podía favorecer ambas dimensiones.

El mismo año de la publicación que acabamos de mencionar, David Stitchkin Branover sucedió en la rectoría de la universidad a Enrique Molina Garmendia, marcando una etapa de reformas que actualizó el perfil de la institución. Su renovado compromiso con el desarrollo económico, social y cultural de la zona se dejó sentir en la comunidad gracias a la prolífica actividad extensional. De este modo el vínculo identitario se expandió, abarcando un espectro social más amplio.

En relación con la circulación, en 1952 y 1954 aparecen la orquesta y coro universitarios respectivamente. Ambas agrupaciones eran relativamente autónomas, pero sostenidas por la universidad, y deben haber contribuido a la divulgación del nuevo himno en una magnitud mucho mayor de la que había sido posible con los anteriores. Especialmente el coro, por sus facilidades logísticas. Adicionalmente, ambas agrupaciones pasaron por la dirección de Junge en aquellos años, asunto que debemos tener muy en cuenta al revisar la última parte de esta historia.

Por último, todo esto debió verse reforzado además por los medios de comunicación masivos, gracias a la creación de Radio Universidad de Concepción en 1959, que se encargó de registrar y transmitir buena parte de las actividades oficiales que se realizaban, habitualmente iniciadas con la ejecución del himno.

En adelante, cerrar el ciclo fue solo una dilatada cuestión de tiempo. En 1964 Junge acepta la paternidad de la pieza al inscribirla en el Registro de Propiedad Intelectual N 28591. Supuestamente, desde entonces pasó a ser oficialmente el emblema sonoro de la Universidad de Concepción. La frase inaugural de su estribillo "por el desarrollo libre del espíritu", ya había sido reconocida como lema ${ }^{99} \mathrm{y}$, sobre todo, como una declaración fundamental de principios dentro de una institución que se autodefine como autónoma, laica y pluralista. Una imagen que la propia comunidad local demostraba sostener respecto de la institución.

En 1981, durante el mandato del rector designado Guillermo Clericus Etchegoyen, se iniciaron las gestiones para la tramitación de "las inscripciones en el Registro respectivo de Propiedad Intelectual del Ministerio de Economía, del Escudo Universitario, con el lema 'Por el desarrollo libre del espíritu' y recientemente del Emblema o Bandera de nuestra Universidad"100; "La intención es adquirir los derechos o bien asegurar el uso exclusivo de la canción por parte de la universidad. Se aclara que el señor Yunge (sic) -quien por entonces oficiaba de Director en la Orquesta Sinfónica de la Universidad de Concepción- viene

\footnotetext{
99 Se la utilizaba, por ejemplo, en la prensa de época. La Patria, 22 de abril de 1944, p. 3

100 AC, UdeC. Exp. 81-370. Carta de Rectoría 81-1377, de Gustavo Villagrán Cabrera, Secretario General, a Enrique Fuenzalida P., Asesor Jurídico, 2 de julio de 1981.
} 
percibiendo desde hace años e irregularmente los pagos correspondientes a la norma del Pequeño Derecho de Autor, "de manera que es justo indemnizarle por ello"101.

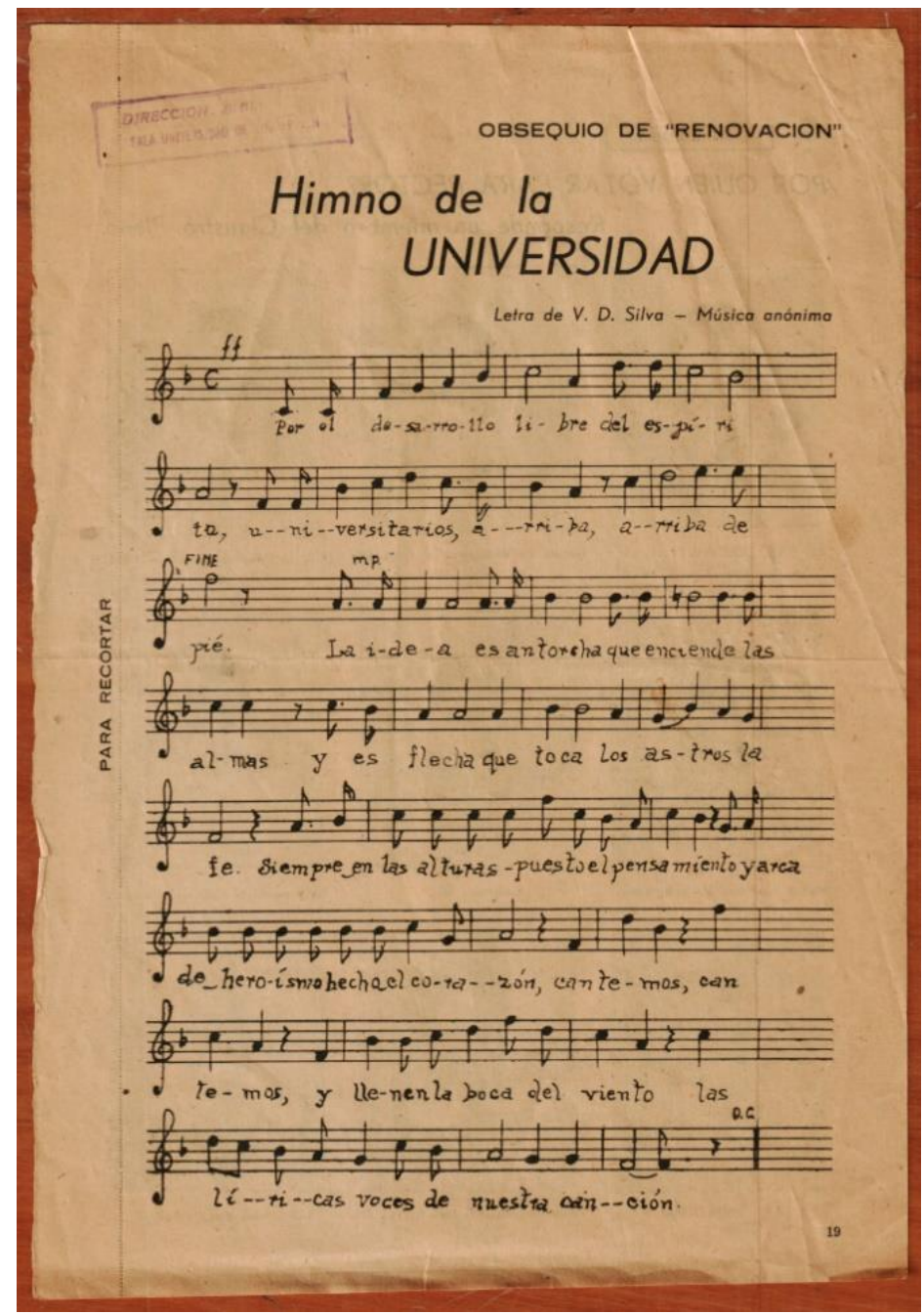

Imagen 6. Melodía del Himno de la Universidad de Concepción publicada en Renovación. Fuente: Universidad de Concepción, Biblioteca Central Luis David Cruz Ocampo, Sala Chile, AVSCH-SU-H-22.

Las gestiones hechas en el intertanto derivan en una carta por parte del músico donde expone largamente su posición. Comienza mencionando algunos premios otorgados recientemente por concepto de creación de himnos -Chillán, $\$ 60.000$ y Villarrica, $\$ 50.000-$, donde el monto de este último habría sido considerado demasiado exiguo por parte del jurado.

101 lbíd. 
En el caso del himno de la Universidad, como es sabido, este logró imponerse ampliamente y por sí solo, por lo cual debiera talvez ser considerado como una obra comisionada, en cuyo caso el honorario lógicamente es más elevado que un simple "Premio" estipulado en un concurso ${ }^{105}$.

Ante esta intención de conferirle vida propia a su pieza musical, recordemos que el autor estuvo esporádicamente a la cabeza de los principales conjuntos musicales universitarios durante el periodo en que había decantado en la comunidad.

A modo de sugestiva referencia, Junge menciona su reciente premio en el Concurso Nacional de Composición organizado un año antes por la Pontificia Universidad Católica de Chile -se refiere al obtenido por su Cantata del pan y la sangre-, por un monto de U\$2.500, equivalente a unos $\$ 100.000$, donde frente a las exigencias del concurso "constituían una cantidad francamente ridícula. Sin embargo -prosigue-creo que esa suma podría servir como base para el Himno, siempre en el supuesto que el Pequeño Derecho de Autor me siga siendo pagado como habíamos estipulado en principio" ${ }^{106}$.

Tras insistir en la diferencia proporcional entre una cantata y un himno, y adicionalmente entre un premio por concurso y una obra comisionada, cierra su carta con la siguiente sentencia: "creo que debe ser debidamente ponderada la forma como el himno ha logrado arraigarse en nuestro medio... y escribir un himno que logre eso, también es arte" ${ }^{107}$.

Al día siguiente se ordenó comunicar a Wilfried Junge una oferta por U\$2.500 ${ }^{108}$, aunque quedará pendiente una aclaración respecto del mencionado Pequeño Derecho de Autor ${ }^{109}$. Esta alusión de Junge buscaba asegurar que, sobre la suma pagada por la universidad, continuará percibiendo un monto por cualquier presentación o reproducción que se realice de la obra ${ }^{110}$. Es decir, su intención última no era la venta incondicional de los derechos sino solo una cesión de exclusividad, tratada en términos muy diplomáticos.

Las negociaciones llegaron a un aparente buen término pues, bajo las condiciones requeridas, pocos días más tarde se solicita al rector autorizar la suma ofertada, por concepto de "compra de derechos sobre propiedad intelectual a D. Wilfried Junge E. por Himno de la

${ }^{105}$ AC, UdeC. Exp. 81-370. AJ N² 299 (recibida): carta de Wilfried Junge Eskuche al Asesor Jurídico, 12 de julio de 1981. Las cursivas son añadidas.

106 Ibid.

107 Ibid.

${ }^{108}$ AC, UdeC. Exp. 81-370. AJ Nº 422/81: carta del Asesor Jurídico al Secretario General, 13 de julio de 1981.

${ }^{109}$ AC, UdeC. Exp. 81-370. Carta de Rectoría 81-1539, 17 de julio de 1981, y AJ N 447/81, 21 de julio de 1981.

110 Ley 17.336, Artículo 110, del Ministerio de Educación Pública (1970). En https://www.leychile.cl/Navegar?idNorma=28933\&buscar=peque\%C3\%B10+derecho+de+autor (Visitado en 15-032020) 
Universidad de Concepción" ${ }^{111}$, con respuesta positiva y definitiva para el 18 de agosto de $1981^{112}$.

En todo caso, Junge aprovechó la instancia para emplazar a la universidad respecto de su situación contractual "ya que en la actualidad posee la calidad de Director Adjunto de la Orquesta y no de Director Titular, aunque desde el $1^{\circ}$ de julio se desempeña como titular de la Orquesta" ${ }^{113}$. Un final feliz en lo que a él respecta.

\section{Epílogo y consideraciones finales}

A fines de 1986, en una nota "reservada", manuscrita, enviada al Secretario General de la universidad, el rector designado Carlos von Plessing le encargó investigar sobre el pasado desconocido del himno de la Universidad de Concepción ${ }^{114}$. Esto a fin de responder a la carta expedida por Mercedes, una de las hijas de Próspero Bisquertt. Allí, además de respaldarse con diversos documentos, la remitente declaró lo siguiente:

“...me asombra (por decir lo menos) leer en la Guía del Estudiante 1986, editada por la Vicerrectoría Académica de la Universidad de Concepción, que figure en la página 4 como autor de la música del Himno de la Universidad de Concepción el señor Wilfried Junge, y que el nombre del destacado músico Próspero Bisquertt (autor de esa música) haya sido omitido en forma completa y grave". ${ }^{115}$

En respuesta, el rector explicará en parte la extinción del antiguo himno aclarando que "nunca se utilizó la música de la que es autor el maestro Bisquertt, por razones técnicas de ejecución y, transcurridos más de diez años, [Junge] compuso una música que empezó a ser ejecutada por el naciente Coro de la Universidad que él dirigió"116. Si bien algunos de los antecedentes que entrega, como ya hemos visto, son errados, es asertivo al intuir en el uso social del nuevo himno la causal de su permanencia.

Comprender el itinerario histórico que conduce desde la intención hasta la regularización definitiva del Himno de la Universidad de Concepción, en un extenso proceso de casi seis décadas, nos obliga a situarnos en los diferentes escenarios que van condicionando las acciones y determinaciones de quienes participan en él.

\footnotetext{
${ }^{111}$ AC, UdeC. Exp. 81-370. Carta de Carlos von Plessing B., Vicerrector Académico, a Guillermo Clericus E., Rector, 4 de agosto de 1981.

112 AC, UdeC. Exp. 81-370. Carta de Rectoría 81-1833, de Carlos von Plessing B., a Hervi Lagos C., Vicerrector de Administración Financiera y de Personal, Rector, 18 de agosto de 1981.

${ }^{113}$ AC, UdeC. Exp. 81-370. AJ N 534-81: carta del Asesor Jurídico al Secretario General, 24 de agosto de 1981.

${ }_{114}$ AC, UdeC. Exp. 81-370. Nota manuscrita con timbre de Rectoría, 1 de diciembre de 1986.

${ }_{115}$ AC, UdeC. Exp. 81-370. Carta de Mercedes Bisquertt Z. de Krause a Carlos von Plessing, 25 de noviembre de 1986.

${ }^{116}$ AC, UdeC. Exp. 81-370. Carta de Rectoría N 86-3952, 5 de diciembre de 1986.
} 
En una primera etapa el asunto se debate entre la relación entre la institución y la comunidad imaginada, en el decir de Anderson ${ }^{117}$. O, en otros términos, entre la comunidad intra universitaria y la comunidad extendida, aquellos que se suponen tocados por la presencia y accionar de la institución. En ese sentido, el carácter abierto del concurso realizado en 1938 parece haber despertado un fuerte sentido de identificación local a pesar de su alcance nacional, sustentado en la mera posibilidad de hacerse parte. Este sentimiento parece retroceder con el contraste que marca la convocatoria cerrada de 1939 y revitalizarse con la oportuna intromisión de Junge, a principios de los' 50.

En mayor o menor medida, observamos la influencia de círculos sociales específicos en los diferentes niveles de éxito obtenidos por cada agente involucrado, especialmente durante el concurso por la musicalización. Si bien la intención es conseguir una obra de alto nivel que sea representativa del prestigio que supone la primera universidad de provincia, los alcances colaterales asociados específicamente al mundo de la música académica comprometen participaciones significativas en la esfera de poder asociada, espacio donde se conectan los círculos sociales de Concepción y Santiago. De este modo, se trasciende el influjo local de la casa de estudios. Aunque sería justo decir, dado que no hay un rotundo conflicto de intereses, que los asuntos de la institucionalidad musical y universitaria simplemente se pasan por el lado, llegando apenas a rozarse. Así y todo, cuando ese roce ocurre evidencia las maquinaciones que se urden entre cuatro paredes.

Podemos interpretar esta dinámica a partir de la idea de sociabilidad aportada por Aghulon, con las necesarias adaptaciones contextuales y enriquecida por la mirada sociológica de Bourdieu, donde las posiciones relativas de los actores se encuentran altamente determinadas por el capital social, pero al mismo tiempo, el conflicto se sitúa en la intersección de dos espacios de poder, dos campos, que todavía se rigen por sistemas de reglas diferentes. Si antes se había demostrado que Arturo Medina utilizó su cercanía con el círculo asociado a la institucionalidad musical emergente para asegurar la influencia de la Corporación Sinfónica de Concepción y su autonomía respecto de la universidad local, tiene sentido afirmar que pudo haber instrumentalizado el concurso abierto por esta última para afianzar sus vínculos con dicho círculo, capitalizarlos como beneficio a futuro.

En el caso de Junge, en la década de 1950 se encontraba en una posición ventajosa que le permitió asegurar la escucha social de su himno, al frente de los conjuntos universitarios y legitimado como protegido de Medina. Una situación muy diferente a la de tres décadas más tarde, con un himno ya decantado en la comunidad, pero debiendo negociar los beneficios conexos en el marco de una institución mucho más burocratizada y con una gobernanza

\footnotetext{
${ }^{117}$ Anderson, Benedict. 1993. Comunidades imaginadas. Reflexiones sobre el origen y la difusión del nacionalismo, México D.F., Fondo de Cultura Económica.
} 
altamente jerarquizada, designada por la dictadura militar. Acá bien poco puede hacerse en términos de círculos sociales. En cambio, la estrategia es apoyarse en la legalidad vigente y aprovechar la oportunidad que se le abre para poner en juego su capital social acumulado y negociar con la rectoría otros beneficios que, de otra manera, hubiese sido mucho más trabajoso obtener.

Y en todo caso, respecto de la asimilación del himno y su visibilidad, todas estas vicisitudes han pasado a un segundo plano pues lo que queda son sus constantes apariciones en las ceremonias, en la Radio Universidad de Concepción, en el Campanil o en una que otra reunión informal donde la camaradería hace aflorar el sentimiento de pertenencia e identidad de la comunidad imaginada. Y el grueso de esta no conoce de intrigas de poder, sino que simplemente acoge el símbolo en la medida que las condiciones ayuden a percibirlo, aunque sea intuitivamente, como bien simbólico común.

No hay que extrañarse entonces que von Plessing haya ignorado la existencia del himno de Bisquertt. Probablemente su reacción haya sido similar a la de muchas otras personas a quienes recientemente les he mencionado la existencia de otros himnos. "Yo pensé que este había sido desde siempre". Por cierto, una declaración bastante decidora respecto del arraigo y la apropiación del símbolo. Y es que esa parte de la historia institucional, enterrada entre el polvo y los papeles, ha ido quedando ajena a la memoria de una experiencia que, para quienes se han vinculado con la Universidad de Concepción en los últimos 70 años, ha sido construida de la mano de esa melodía ascendente que, en los primeros compases, direcciona el lema de la universidad hacia las alturas, el idealizado lugar del pensamiento.

\section{Fuentes y bibliografía}

\section{Fuentes}

Actas de Directorio, Actas de Consejo Superior y documentación de Rectoría. Archivo Central, Universidad de Concepción.

Archivo AVSCH-SU-H. Sala Chile, Biblioteca Central Luis David Cruz Ocampo, Universidad de Concepción. Archivo de la Corporación Sinfónica de Concepción.

Archivo Enrique Soro.

\section{Diarios y revistas}

Diario El Sur (Concepción).

Diario La Patria (Concepción).

Diario El Imparcial (Santiago).

Diario El Mercurio (Santiago).

Diario La Hora (Santiago).

Diario La Nación (Santiago).

El Diario llustrado (Santiago).

Revista Musical Chilena. 


\section{Bibliografía}

Anderson, Benedict. 1993. Comunidades imaginadas. Reflexiones sobre el origen y la difusión del nacionalismo, México D.F., Fondo de Cultura Económica.

Campos H., Fernando. 1979. Historia de Concepción 1550-1970, Santiago, Editorial Universitaria.

Cartes, Armando. 2017. Actas Fundacionales de la Universidad de Concepción, Concepción, Universidad de Concepción.

Claro, Samuel. 1969. Panorama de la música contemporánea en Chile. (Colección de Ensayos $N^{\circ}$ 16), Santiago, Facultad de Artes de la Universidad de Chile.

Claro, Samuel y Jorge Urrutia. 1973. Historia de la música en Chile, Santiago, Editorial Orbe.

Collier, Simon y Satter, William F. 1998. Historia de Chile 1808-1994, Cambridge, Cambridge University Press.

Da Costa, Miguel. 1995. Crónica fundacional de la Universidad de Concepción, Concepción, Universidad de Concepción.

Díaz, Rafael y Juan Pablo González. 2011. Cantus Firmus: Mito y narrativa de la música chilena de arte del siglo XX, Santiago, Editorial Amapola.

Doniez, Roberto. 2011. Palabra de Soro, Valparaíso, Editorial Altazor.

Escobar, Roberto. 1971. Músicos sin pasado. Composición y compositores de Chile, Barcelona, Editorial Pomaire.

Guerra, Cristián. 2019. "La procesión de Próspero Bisquertt: instituciones y mediaciones en torno a una obra chilena en proceso de canonización y la trayectoria de su compositor", en Resonancias 23/44, Santiago, pp. 101-125.

Hodge, Eduardo. 2014. “Félix Armando Núñez en la pluma de Gabriela Mistral: Chile y Venezuela unidos en el tiempo", en Tiempo y Espacio 62, Caracas, pp. 77-92.

Izquierdo, José Manuel. 2011. “Aproximación a una recuperación histórica: compositores excluidos, músicas perdidas, transiciones estilísticas y descripciones sinfónicas a comienzos del siglo XX", Resonancias, 28, Santiago, pp. 33-47.

Masquiarán, Nicolás. 2011. La construcción de la institucionalidad musical en Concepción, 1934-1963, Santiago, Universidad de Chile, Tesis para optar al grado de Magíster Artes mención Musicología.

Masquiarán, Nicolás. 2011. "¡Otra! ¡Otra! Luchas y tensiones en la oficialización de las músicas locales. El caso de Concepción", en Resonancias, 28, Santiago, pp. 19-32.

Masquiarán, Nicolás. 2018. "A través del espejo. Proyecciones contemporáneas al caso Soro”, en Ámbito Sonoro, 5, Valparaíso, pp. 23-35.

Molina G., Enrique. 1956. Discursos Universitarios, Santiago, Nascimiento.

Musri, Fátima. 2013. "Definiciones y ayudas metodológicas para una historia local de la música", en Revista del Instituto Superior de Música, 14, Santa Fé, pp. 51-72.

Peña, María Pilar y Poveda, Juan Carlos. 2010. Alfonso Leng. Música, modernidad y chilenidad a comienzos del siglo XX, Santiago, autoedición con financiamiento del Fondo de Fomento de la Música Nacional.

Pereira S., Eugenio. 1941. Los orígenes del arte musical en Chile, Santiago, Publicaciones de la Universidad de Chile. Disponible en: http://www.memoriachilena.gob.cl/602/w3-article-8671.html (Consultado el 14 de marzo de 2020).

Pérez, Carlos. 2012. En busca del piano perdido (Documental), Santiago, Universidad Diego Portales.

Rengifo, Javier. 1928 (28 de abril). "Los compositores chilenos", en Zig-Zag, Santiago, pp. 81-90. Disponible en: http://www.bibliotecanacionaldigital.gob.cl/bnd/624/w3-article-153686.html. (Consultado el 06 de marzo de 2020) 
Salas Viú, Vicente. 1952. La creación musical en Chile 1900-1951, Santiago, Ediciones de la Universidad de Chile. (Reducción digital.)

Santa Cruz, Domingo. 2008. Mi vida en la música. Contribución al estudio de la vida musical chilena durante el siglo XX, Santiago, Ediciones Universidad Católica de Chile.

Sandoval, Luis. 1911. Reseña Histórica del conservatorio Nacional de Música y Declamación 1840 a 1911, Santiago, Imprenta Gutemberg.

Subercaseaux, Bernardo. 1997. Historia de las ideas y la cultura en Chile, Santiago, Editorial Universitaria. Disponible en: http://www.ideasyculturaenchile.cl/. (Consultado el 14 de marzo de 2020)

Uzcátegui García, Manuel. 1917. Músicos chilenos contemporáneos (Datos biográficos e impresiones sobre sus obras), Santiago, Imprenta y encuadernación América.

Venegas, Fernando. 2002. Domingo Silva Endeiza: Una vida sin detenciones (1882-1960), Limache, Autoedición auspiciada por el Consejo Nacional del Libro y la Lectura.

Vera, Fernanda. 2015. ¿Músicos sin pasado? Construcción conceptual en la historiografía musical chilena, Santiago, Universidad de Chile, Tesis para optar al grado de Magister en Artes con mención en Musicología.

Veyne, Paul. 1984. Cómo se escribe la historia. Foucault revoluciona la historia, Madrid, Alianza.

\section{Recursos online}

www.leychile.cl 


\title{
Apéndice
}

\section{Himnos oficiales de la Universidad de Concepción.}

Los textos presentados a continuación son una transcripción íntegra de las versiones publicadas junto con el anuncio oficial del premio, el 25 de diciembre de $1938{ }^{118}$.

\section{HIMNO DE LA UNIVERSIDAD DE CONCEPCIÓN}

\author{
Coro \\ Por el desarrollo libre del espíritu \\ ¡Universitarios! ¡Arriba! ¡De pie! \\ La idea es antorcha que enciende las almas \\ y es flecha que toca los astros la fe \\ Siempre en las alturas puesto el pensamiento \\ y arca de heroísmo hecho el corazón, \\ cantemos, y llenen la boca del viento \\ las líricas voces de nuestra canción. \\ II \\ Cantemos la gracia de todas las cosas. \\ Riamos, y nuestra risa de cristal \\ caiga en una lluvia de joyantes rosas \\ sobre el ara santa de nuestro ideal.
}

III

Ansia de cultura, lámpara encendida que su albor proyecta sobre el porvenir, tengámosla en alto y amemos la vida que es alfa y omega, cenit y nadir.

IV

Como se nos brinda la naturaleza, así nos entregue la Universidad

118 BC, UdeC, La Patria, 25 de diciembre de 1938, p. 6 
los frutos del Arte -que son de belleza-

y los de la Ciencia, -que son de verdad.

\section{V}

El Aula no es cárcel, ni celdas las salas.

No impone el estudio grillete, ni cruz.

Las hojas del libro que se abre, son alas

con las que ascendemos a esferas de luz.

$\mathrm{VI}$

Libre como el viento que empuja la nube

¡Universitarios! vibre nuestra voz

y escúchese en ella la nota que sube

del polvo a los astros, del hombre hasta Dios.

Brindis

Por el desarrollo libre del espíritu

¡Universitario! Por la plenitud

de los ideales en marcha de triunfo.

Por cuanto embellece la vida... iSalud!

Ñanku (Víctor Domingo Silva)

\section{HIMNO DE LA UNIVERSIDAD DE CONCEPCIÓN}

\section{Coro}

Universidad grande y excelsa, foco vivo de luz ideal.

cien campanas que saben tu gloria

por la patria diciéndola van.

Del talento, palanca del mundo, eres templo, eres cálido hogar.

$Y$ tu nombre en la lid que cumplimos

como un sacro pendón de verdad.

Sobre el aula en que bulle la idea, grave ariel tiende el ala inmortal. 
En tu seno, hecha llama, la ciencia dora el triunfo del ínclito afán.

Si el presente es faena y esfuerzo, el pasado es victoria y laurel.

Cuando brilla la luz de su ejemplo hay un gesto de asombro por él.

$Y$ al futuro nos vamos alegres, brazos plenos del dón que nos das. Dentro dél hay un sol, el saber, $y$ hay un tirso fragante, la paz. Hacia el día que nace elevemos este himno que es rezo y cantar. ¡Que sus notas triunfales resuenen en la sierra, en el valle y el mar! 